\title{
Mamelón: los artesanos gráficos del jerez
}

\section{Resumen}

La ciudad de Jerez tuvo una importante industria gráfica vinculada a la producción del vino que le dio fama. A finales del siglo XIX y principios del XX, para cubrir las necesidades de envasado y promoción publicitaria de sus productos, esta industria se rodeó de profesionales: litógrafos, impresores, y también grafistas. Creadores gráficos que fueron consolidaron un perfil específico muy capacitado no frecuente en otros lugares. Artistas polifacéticos como Teodoro Miciano y una larga lista inician una saga de la que Pro.Gra.Ma. (Proyectos Gráficos Mamelón) constituye una de sus últimas manifestaciones.

Palabras clave: jerez, etiqueta, vino, publicidad, Andalucía

\section{Mamelón: the graphic artisans of sherry}

\section{Abstract}

The city of Jerez had an important graphic industry linked to the production of wine that made it famous. In the late nineteenth and early twentieth centuries, to cover the needs of packaging and advertising promotion of its products, this industry was surrounded by professionals: lithographers, printers, and also graphic designers. Graphic creators who were consolidated a very skilled specific profile not frequent in other places. Multifaceted artists such as Teodoro Miciano and a long list begin a saga of which Pro.Gra.Ma.("Mamelón Graphic Projects") is one of its latest manifestations.

Keywords: sherry, label, wine, advertising, Andalusia 
Apresuradamente, como en los tiempos que llegaba tarde a la escuela, entró Fermín Montenegro en el escritorio de la casa Dupont, la primera bodega de Jerez, conocida en toda España; «Dupont Hermanos», dueños del famoso vino de Marchamalo, y fabricantes del cognac cuyos méritos se pregonan en la cuarta plana de los periódicos, en los rótulos multicolores de las estaciones de ferrocarril, en los muros de las casas viejas destinados a anuncios y hasta en el fondo de las garrafas de agua de los cafés.

Vicente Blasco Ibáñez: La bodega

Esta aproximación a los dibujantes y grafistas jerezanos parte de varias conversaciones con Manuel García Díaz, diseñador natural de Jerez, compañero de profesión, gran maestro en la creación de etiquetas de vinos y licores y mejor persona. Manolo había aprendido su oficio en una empresa peculiar, al menos para mí, una especie de agencia a lo "Bad Men» jerezana, ${ }^{2}$ dedicada a la creación gráfica entre los años cincuenta y los noventa del pasado siglo. Dado que la economía de Jerez de la Frontera ha girado en torno al vino, sus derivados y su industria auxiliar, es fácil imaginar que la principal clientela de esta agencia y de estos creativos fueron las bodegas jerezanas y su entorno.

Las artes gráficas vivieron una gran revolución con la aparición de la litografía a principios del s. XIX, pues posibilitó a los artistas crear su original sobre la misma matriz de reproducción, al tiempo que permitía tonos contínuos, degradados y aguadas, y sobre todo, introdujo la reproducción en color. Esta técnica fue

2 La frase es de Carmen Valle, hija de Manuel Valle Cortés, uno de los fundadores de «Proyectos Gráficos Mamelón». Hace alusión a la serie televisiva con este nombre, y que trata sobre el mundo de la publicidad neoyorkino en los años 50 y 60 . Lo compara con el peculiar ambiente plagado de divertidas anécdotas que ella recuerda de la empresa donde trabajaba su padre. 
introduciéndose paulatinamente en España y no es, hasta entrado el siglo XX, que la reproducción mediante fotograbado en relieve, las técnicas fotomecánicas y el offset cubren las necesidades de los talleres. Aún así, la litografía tuvo su uso específico en Jerez hasta los años cincuenta, cuando queda finalmente relegada. Incluso estando presentes las posibilidades de la fotografía para el uso publicitario, en España sigue manteniéndose la figura del «dibujante comercial», o publicitario, que realiza los originales a mano, con pluma, tinta, témperas y anilinas. Incluso hasta los años ochenta era posible encargar fotograbados tramados para la impresión en relieve. Como decíamos, el offset estaba plenamente introducido en los sesenta, y el desarrollo fotomecánico necesario para los montajes había reemplazado el trabajo del litógrafo sobre piedra. La fotocomposición se había introducido en los talleres fotomecánicos, relegando la composición de tipos en relieve y simplificando las tareas de montaje de textos y páginas. Aún así, era necesario disponer de equipos muy costosos, con los que solo podían contar los talleres fotomecánicos.

En el cambio de los ochenta a los noventa, el ordenador personal aplicado a las artes gráficas irrumpe y, en pocos años, desplaza los usos tradicionales de la fotomecánica, convirtiendo los procesos gráficos en procedimientos digitales. Pero quizás el efecto más inmediato fue que puso en manos del diseñador herramientas que sólo podían usarse de forma mediatizada hasta el momento: el diseñador preparaba los artes finales cuidadosamente en un conjunto de dibujos, maquetas e instrucciones que debían ser interpretados y reelaborados por personal especializado. En cambio, a partir de ahora, preparará los textos y las imágenes, para reunir su trabajo en un archivo digital, listo para su impresión, reduciendo enormemente las fases de producción. Este cambio tuvo grandes ventajas, pero también produjo un gran cambio en la forma de concebir y elaborar los proyectos, pues fases que se realizaban manualmente quedaban relegadas al mero deseo de hacerlas, pues era relativamente fácil cubrirlas con procesos digitales. Podemos decir que, por un lado, el diseño se hizo más conceptual y la velocidad de dichos procesos se aceleró, dejando menos espacio para la reflexión. Todo avance tiene sus costes, como afirma Virilio (1997):

No hay ganancia sin pérdida. Cuando se inventa un objeto técnico, el ascensor, por ejemplo, se pierde la escalera; cuando se inauguraron las líneas aéreas transatlánticas, se perdió el paquebote. (pp. 35-36)

Toda transformación histórica genera posiblemente avances pero también pérdidas inevitables. Hanna Arendt reflexionó sobre la ruptura con la «tradición» que han supuesto los cambios sociales y culturales del siglo XX, y su análisis sigue siendo de plena actualidad. Más allá de una postura romántica y de añoranza del pasado, lo que la filósofa plantea es si somos capaces de darnos cuenta qué perdemos con los cambios, y cuanto de olvido de la tradición sacrificamos con cada transformación. Perdemos o modificamos hábitos sociales y culturales, transformamos una forma de "pertenecer a un mundo", sumidos en la ceguera de no advertir qué es lo valioso que se pierde en cada época, aquello que nos acerca a algo que proviene del pasado y que de alguna manera permite que se proyecte de un modo positivo hacia el futuro (Arendt, 2018). La actividad creativa no se sustrae a estas transformaciones. Cada avance o innovación supone relegar o abandonar técnicas y procesos, pero también formas de expresión que desaparecen.

Esta aceleración y abaratamiento de los procesos dio lugar a la desaparición de esta «tradición» profesional. Esta transformación radical de las condiciones técnicas y sociales creemos que produjo una fractura entre la generación a la que hacemos referencia y las nuevas, y más allá de su ámbito local, estas personas son prácticamente desconocidas. Por ello creemos interesante recuperar del olvido a los autores, sus trabajos y su «saber hacer», más allá del mero registro documental. Conocer qué los hizo ser lo que fueron, cómo trabajaban y orientaban sus creaciones, y con ello, «aprender de su práctica». (López Marín, 2013 y 2017). 


\section{La industria del vino en Jerez}

Jerez de la Frontera es una ciudad peculiar por varios motivos: es conocida internacionalmente por su vino, así como otras señas de identidad: sus caballos o su profunda relación y claro protagonismo para el Arte Flamenco, y su reciente vinculación con el motociclismo, por ejemplo. Sin embargo, estos lugares comunes ya frecuentados no hacen sino ocultar una realidad más compleja y diversa. Sin ser una capital de provincia, sus habitantes —más de 200.000—, su término municipal —uno de los más extensos de España—, así como su actividad económica la destacan por encima de muchas de ellas.

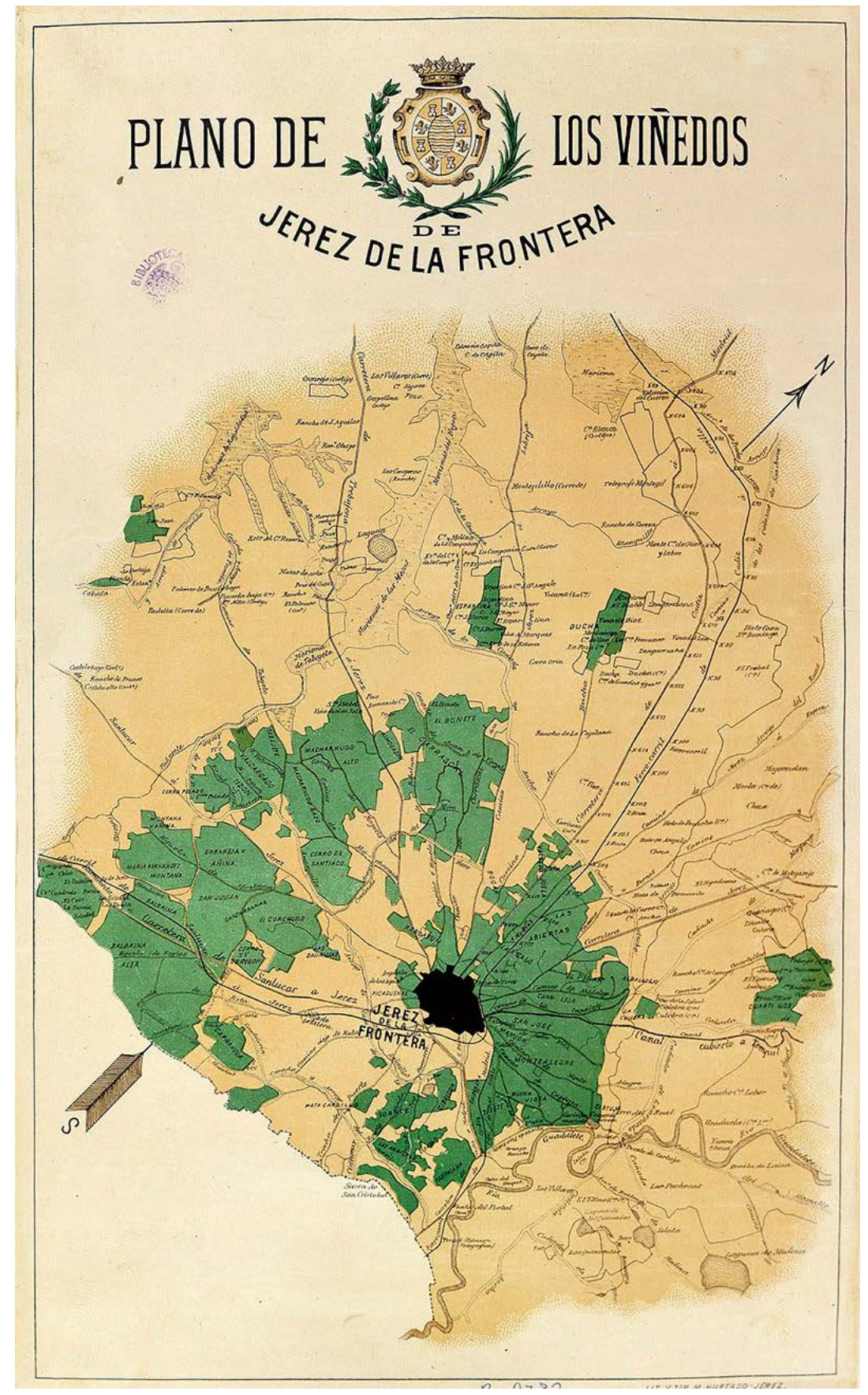

Fig. 1. Plano de los viñedos de Jerez de la Frontera (1897).

Lit. y Tip. M. Hurtado, Jerez. BDH, Biblioteca Nacional de España. 
Desde tiempos remotos, la comarca de Jerez fue famosa por su producción vinícola, y esta realidad, más allá de su significado cultural e histórico, ha tenido claras repercusiones en su vertebración social y desarrollo industrial. Desde el siglo XIX, y a raiz del negocio del vino, familias de cosecheros, almacenistas y exportadores extranjeros, franceses e ingleses especialmente, y el éxito comercial de los productos en los mercados foráneos dieron lugar a una incipiente burguesía que se destacó frente a las de otras provincias, erigiéndose en una «aristocracia del vino» selecta y distinguida, vinculada a la vieja nobleza agrícola de Jerez (Maldonado Rosso, 1999).

El trabajo necesario para el cultivo de las vides fundado en latifundios y la obtención de vinos y licores conformó una clase social de jornaleros y obreros vinculados a las bodegas y su producto. Al tiempo, otras actividades especializadas se dieron lugar para completar las necesidades de esta estructura económica: toneleros, caldereros, botelleros, carpinteros, etc., junto con administrativos, contables, así como todo tipo de artesanos, dieron vida a una floreciente economía que se desarrolló desde mediados del siglo XIX, con terribles crisis y reconversiones a sus espaldas, hasta el momento actual.

El Real Decreto de 20 de noviembre de 1850 establece en España una normativa legal para la regulación del uso de marcas comerciales. A partir de entonces, fabricantes y propietarios de estos «certificados de marca» pueden defender sus derechos frente a posibles imitadores y usurpadores (Gómez Díaz-Franzón, 2018). Hasta ese momento - y todavía durante muchas décadas - el vino de Jerez había sido exportado en botas y envasado y comercializado con denominaciones del exportador en los mercados finales, como el Reino Unido. Es en el ámbito nacional y latinoamericano donde el vino se embotella, por lo que se inicia una demanda de soportes identificadores: envases, reclamos publicitarios, etiquetas y carteles. Para esta labor, los productores habían utilizado botellas procedentes de los lugares más diversos (Alemania, Francia, Bélgica) y hasta 1896 no se crea la primera fábrica de botellas en Jerez. El modelo utilizado será la botella «jerezana» de color negro (González Gordon, 1970, p. 491).

A partir de los años treinta, tras la caída del mercado británico a finales del XIX y la crisis de la filoxera a principios del XX, la industria del vino en Jerez conoce un nuevo florecimiento. Esta vez se asientan las bases para retener actividades de marcado valor añadido, como era el embotellado en origen de los productos, que se venían haciendo en los mercados de destino. De esta forma se intentaba evitar los fraudes, como las mezclas con productos de imitación. Curiosamente, la exportación mayoritaria de vino de Jerez se realizó en botas de 500 litros hasta los años 60 del siglo XX, con lo cual, el vino exportado no necesitaba etiqueta ni envase que lo identificara. Este cambio de estrategia generó la aparición de industrias auxiliares: botellería, talleres de impresión de etiquetas y todo tipo de impresos comerciales, fabricación de tapones y cápsulas, cajas de madera para el transporte, etc. También es a principios del siglo cuando se diversifican los productos, como fue la elaboración del brandy, que generó una larga controversia en torno a su denominación (Melendreras, 1949, pp. 21-23). Así, la edad dorada de la industria vinícola jerezana empieza en los años treinta y se desarrolla en las décadas que van desde los cuarenta hasta prácticamente los ochenta. La integración de España en la Comunidad Europea coincide con grandes cambios en los gustos del público en cuanto al consumo de las bebidas alcohólicas y el vino en particular, y da lugar a la total reconversión de esta industria. Al mismo tiempo se produce un cambio radical en las relaciones laborales y económicas en las empresas del sector, con fuertes concentraciones, cierres empresariales y la transformación del cultivo de la vid y sus productos. 


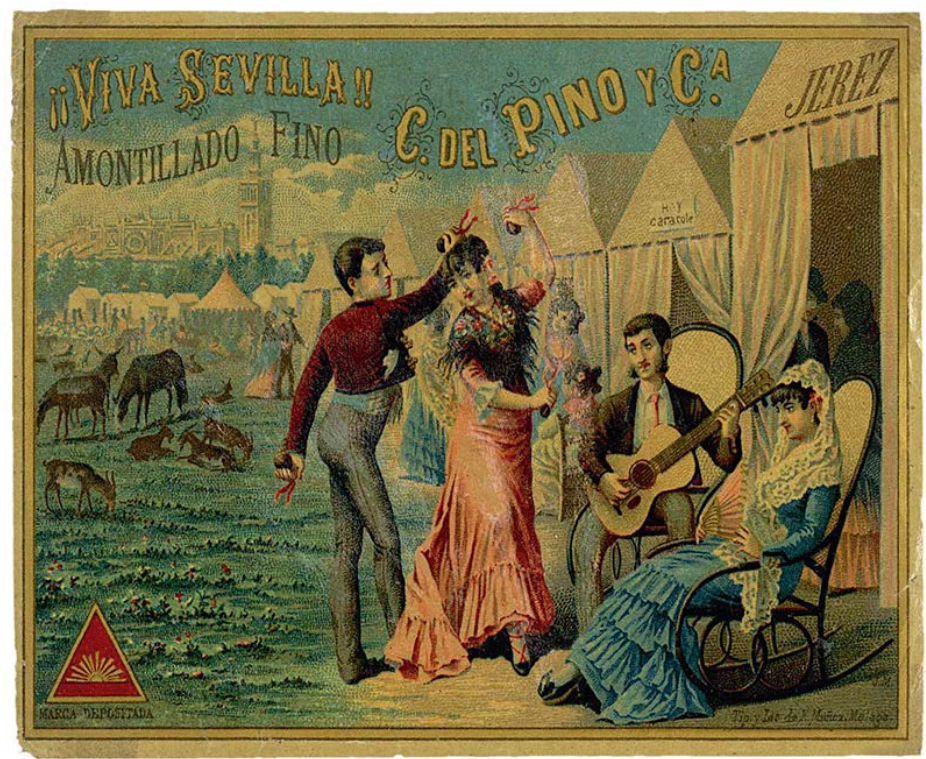

Fig. 2. Etiqueta «amontillado fino C. del Pino y Cia.» (entre 1890 y 1920). Litografía F. Muñoz, Málaga. BDH, Biblioteca Nacional de España.

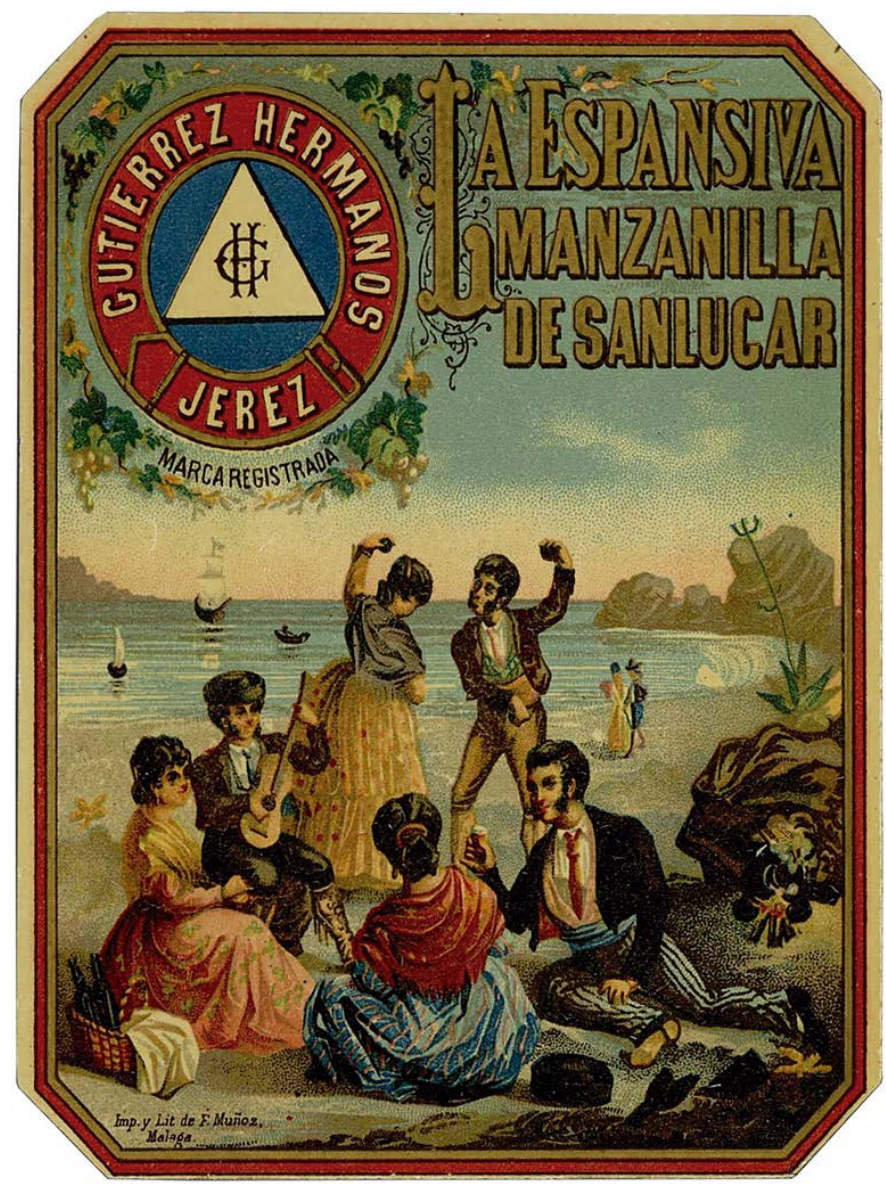

Fig. 3. Etiqueta «manzanilla Gutiérrez Hermanos» (entre 1890 y 1920). Litografía F. Muñoz, Málaga. BDH, Biblioteca Nacional de España. 


\section{Las artes gráficas en Jerez}

En este contexto se desarrolló una de la industrias auxiliares más dinámicas que han existido en Andalucía, como fueron los talleres gráficos - litográficos, tipográficos en un principio, y offset, manipulación y embalaje posteriormente- que dieron servicio al mundo del vino y a sus necesidades comunicativas. A mediados del siglo XIX esta demanda estaba siendo cubierta por empresas catalanas, levantinas, malagueñas, o incluso francesas, que enviaban a sus agentes con sus catálogos a Jerez. El desarrollo de las artes gráficas atrajo a profesionales de otros lugares al tiempo que posibilitó la consolidación de profesiones que no eran frecuentes en estas tierras, como fue la de dibujante, litógrafo, impresor, etc.
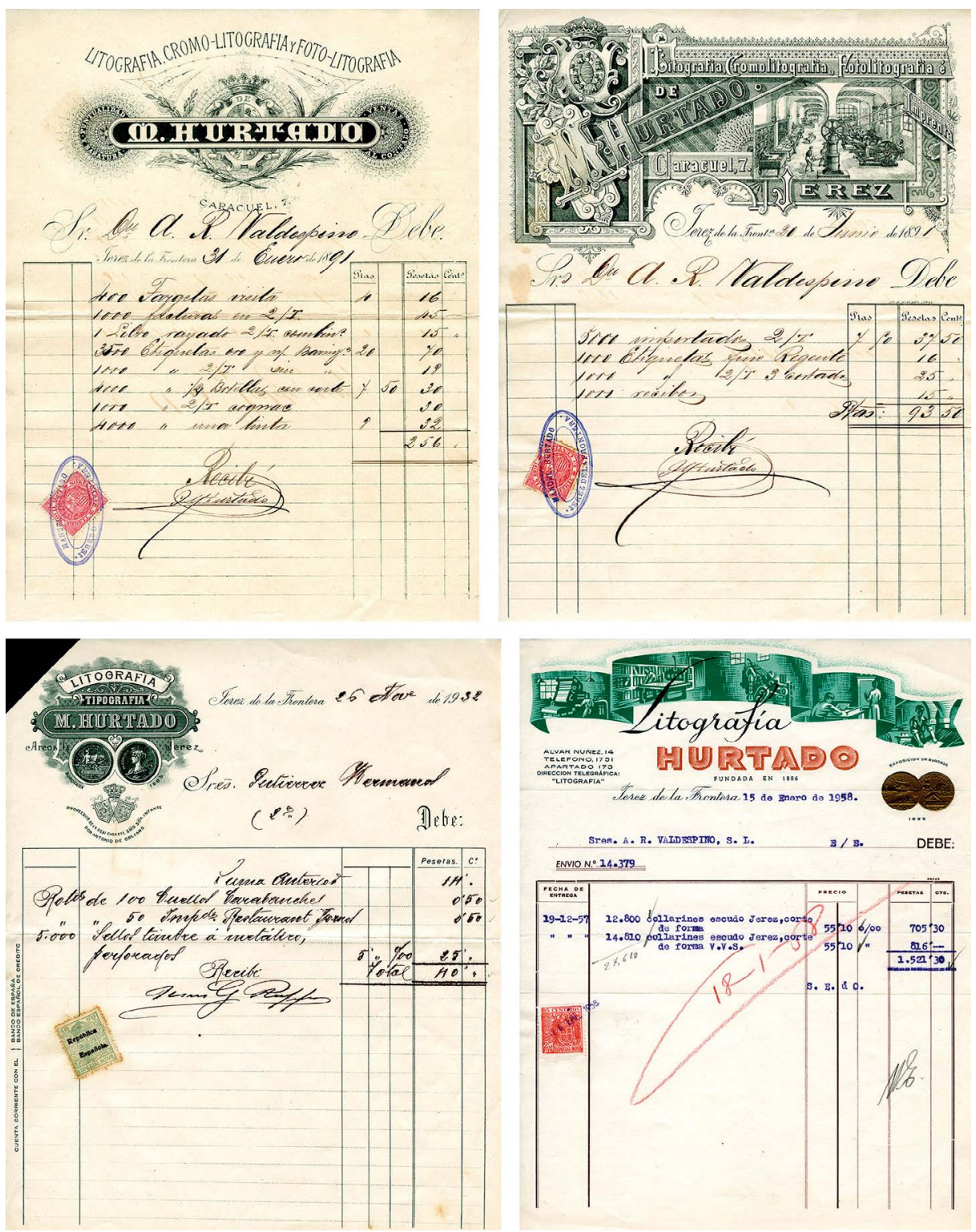

Fig. 4. Factura. Litografía Hurtado, Jerez (enero 1891). Colección particular.

Fig. 5. Factura. Litografía Hurtado, Jerez (junio 1891). Colección particular.

Fig. 6. Factura. Litografía Hurtado, Jerez (1932). Colección particular.

Fig. 7. Factura. Litografía Hurtado, Jerez (1958). Colección particular. 
Tras la implantación en Jerez en 1868 del establecimiento de la Litografía Müller que Jorge Wassermann había fundado en Cádiz en 1861 especializada en etiquetas, carteles e impresos comerciales, otras iniciativas tuvieron lugar, como la de Manuel Hurtado de Mendoza, malagueño, que se instala en Jerez en 1866; la Litografía Jerezana de Francisco Rodríguez en 1897; o la de los hermanos Salido, que tras sucesivas separaciones y posteriores fusiones, dieron como resultado la denominación Jerez Industrial en 1937, que terminaría convirtiéndose décadas después en un importante e influyente grupo de empresas que cubrían todos los procesos de la industria gráfica y el embalaje (ABC, 1970, p.18).

A finales del siglo XIX ya existe en Jerez la Sociedad de Artes Gráficas que reúne a los trabajadores especializados de la industria (litógrafos, tipógrafos, dibujantes), que velaban por la calidad y el buen hacer en su oficio. Su actividad es tal que envían delegados a la Exposición Universal de Paris de 1900, para conocer los adelantos técnicos que en ella se muestran. Quedan tan admirados de la perfección de esta industria y el reconocimiento de sus profesionales, que en su informe comentan:

Dicho se está que lo principal que se necesita para obtener esta clase de trabajos, es un buen grabador, un inspirado artista, que tenga la suficiente práctica y dominio sobre tales trabajos; y esos artistas, cuando están poseídos de su verdadero valer, remontan los vuelos hasta esos grandes centros, donde únicamente pueden encontrar merecida retribución sus obras, alejándose de aquellos lugares donde, más que vivir, vegetan, embotándoseles los sentidos, cuando no por la explotación á que se les reduce, por los egoísmos de que se ven rodeados. Por eso creemos que en España, donde tan poco se protegen las artes y con tal desdén se miran á los artistas, será difícil que se pueda llegar, ni en ese ramo, ni en otros, á tal grado de perfección. (Téllez Fernández y Ruiz del Castillo, 1900, p. 36)

En el mismo informe defienden la creación de una Escuela de Artes y Oficios en la ciudad:

El Ayuntamiento de Jerez, sobre todo, debiera fijarse en la conveniencia, en la necesidad, mejor dicho, de crear una Escuela profesional de Artes y Oficios, donde recibieran la enseñanza, indispensable los muchísimos aprendices de Imprenta y Litografía [...] llegaría á ser un utilísimo plantel de obreros tipógrafos, litógrafos, dibujantes, grabadores y demás artistas excelentes, para la confección de trabajos perfectos y esmeradísimos en las Artes Gráficas. En nada, tan honroso, tan importante y tan elevado, podría, la ciudad invertir grandes sumas como en la creación de esa institución magnífica, de cultura exquisita y adelantos positivos, lo mismo para, prosperidad de nuestro pueblo, que para bienestar y dignificación de sus obreros inteligentes. (Téllez Fernández y Ruiz del Castillo, 1900, p.93)

La Escuela se fundaría diez años después. En 1913, la Revista Nuevo Mundo realiza un reportaje sobre Jerez, y uno de los artículos versa sobre las artes gráficas en la ciudad. En él, se explica como, en la Litografía Jerezana por ejemplo, y gracias a la inquietudes y la conciencia social de su director, Manuel Olías, los trabajadores realizan jornadas de ocho horas y tienen derecho a la remuneración completa en caso de baja por accidente. Esta empresa tiene ya cien trabajadores, con la última maquinaria del sector, como una rotativa litográfica en zinc, y cuenta con una escuela de dibujantes litógrafos (El Bachiller Bambalina, 1913, pp. 13 y 32). Aquellos jóvenes que tenían habilidades para el dibujo enseguida vieron abiertas las puertas de talleres necesitados de aprendices del oficio. Con el paso del tiempo, estos «artistas» generaron ciertas escuelas, estilos y formas de entender su actividad, al tiempo que elevaron la calidad y dignificaron su profesión.

\section{Jerez y los dibujantes del vino}


En torno a esta industria gráfica durante varias generaciones se formó un plantel de dibujantes que, sin constituir un grupo conscientemente homogéneo, pueden ser identificados por unas pautas comunes en cuanto a origen, intereses y formas creativas. En un primer periodo encontramos etiquetas y especialmente publicidad realizada por artistas de renombre internacional, como es el caso del italiano Leonetto Cappiello (1875-1942), conocido como el padre de la publicidad, seguidor de Chéret, es el autor de carteles de las marcas europeas más diversas. Es el caso también del cartel del «Don» de Sandeman, del escocés George Massiot Brown (1881-?), por el que al autor cobró por la cesión de derechos 50 guineas (Halley, 2005, p. 196). Autores españoles como Francisco Hohenleiter (1889-1968) —imagen de las bodegas José de Soto-; Nicolás Soro (1875-1943) —azulejo del león para Domecq—; Carlos González Ragel (1899-1969), con su «esqueletomaquia» en el azulejo de Los Gabrieles de Madrid; Carlos Ruano Llopis (1878-1950) con su cartel del «maletilla» para Domecq; José Luis Torres Fernández (1901-1966), dibujante de etiquetas, rótulos y anuncios; o el destacado grabador Teodoro Miciano Becerra (1903-1974), con una gran obra cartelística, que realizó ilustraciones para la Nueva Litografía Jerezana y fue profesor en la Escuela de Artes y Oficios, y que posteriormente se traslada a Madrid. Es necesario destacar autores como Luis Pérez Solero (1892-1968), autor de la figura del Tío Pepe y de campañas famosas para González Byass, Manolo Prieto (1912-1991), que trabaja en Madrid y realiza el famoso Toro de Osborne; Francisco Mariscal Serrano (1925-1995), autor de interesantes carteles; o el pintor, fotógrafo y cartelista José Ramón Fernández Lira (1935-2010).

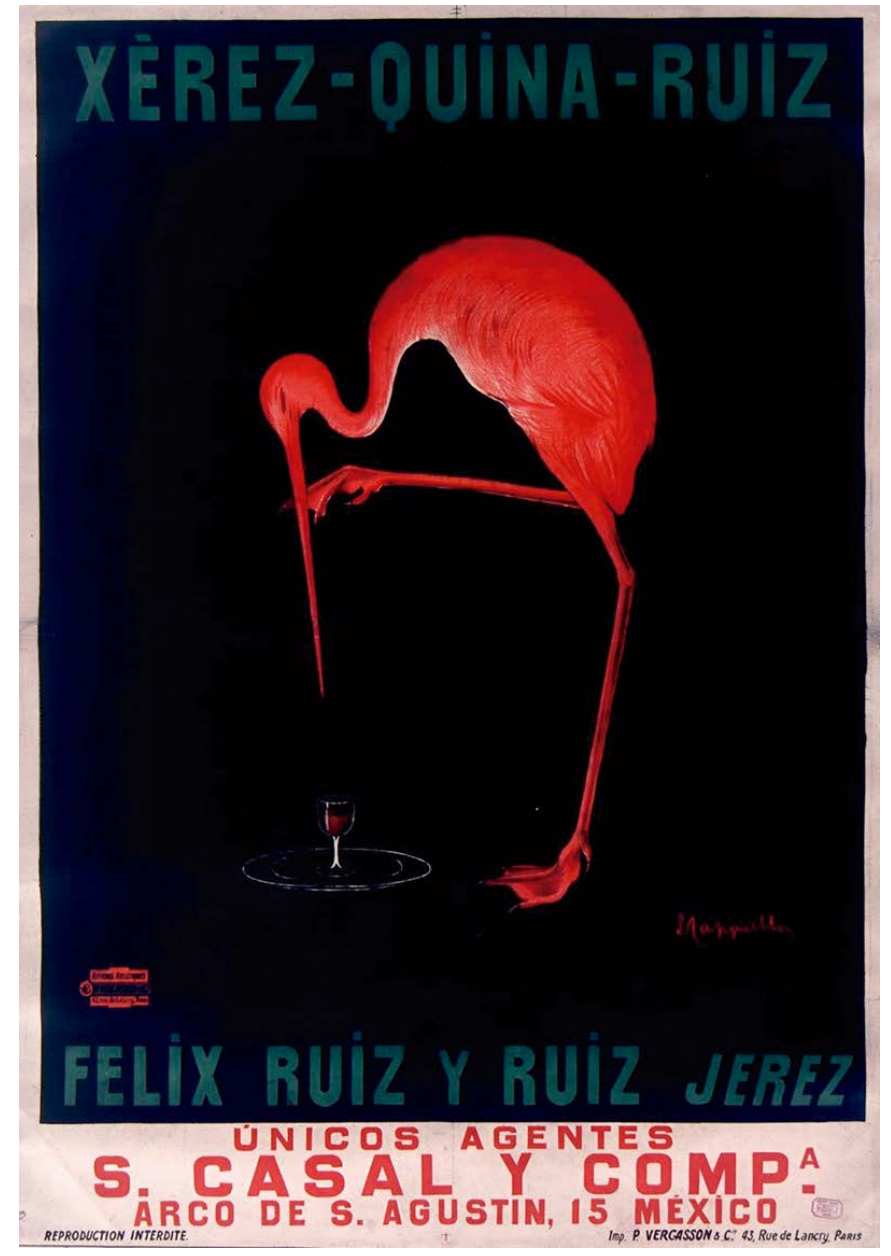

Fig. 8. Leonetto Capiello, cartel «Xèrez-Quina-Ruiz» (1905). Imp P. Vergasson \& Cie, París. Gallica, Biblioteca Nacional de Francia. 
En la literatura sobre la historia del Diseño en España no es frecuente encontrar referencias a Andalucía anteriores a los años ochenta. Si aparecen, aluden al cartelismo del siglo XIX o al envasado de productos, y salvo los primeros, realizados por pintores, el resto suele ser obra de manos anónimas. El caso singular de Manolo Prieto aparece aislado, e incluso el autor de la imagen del Tio Pepe de González Byass pasaba inadvertido en las historias del Diseño en España (Satué, 1997, p. 73). Este vacío, cubierto en parte por algunas tesis doctorales relativamente recientes, hace que la imagen que se tenga del Diseño sea incompleta y, en cierta medida, injusta. También habría que decir que los perfiles profesionales que cubren los autores que mencionamos es amplio, pues nos encontramos desde litógrafos, dibujantes, caricaturistas, rotulistas o publicitarios, entre otras actividades. Pero todas ellas tienen el denominador común de su actividad en torno a las bodegas y lo que las rodea, y en cierta forma proceden de una «escuela común». Y por otro, estas actividades pueden estar claramente vinculadas al diseño de comunicación hoy más que antes.

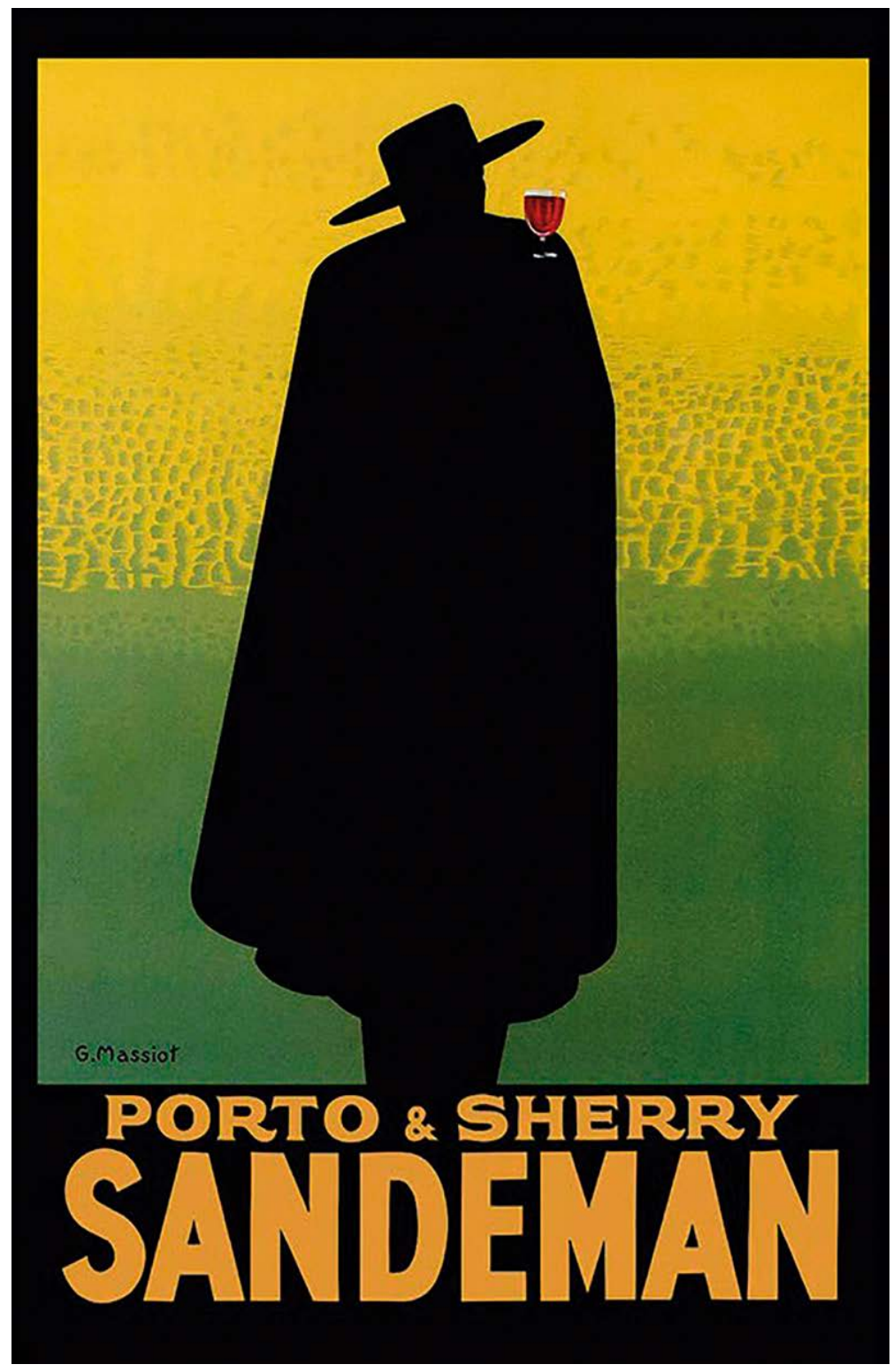

Fig. 9. George Massiot, cartel «Porto \& Sherry Sandeman» (1931). Colección particular. 


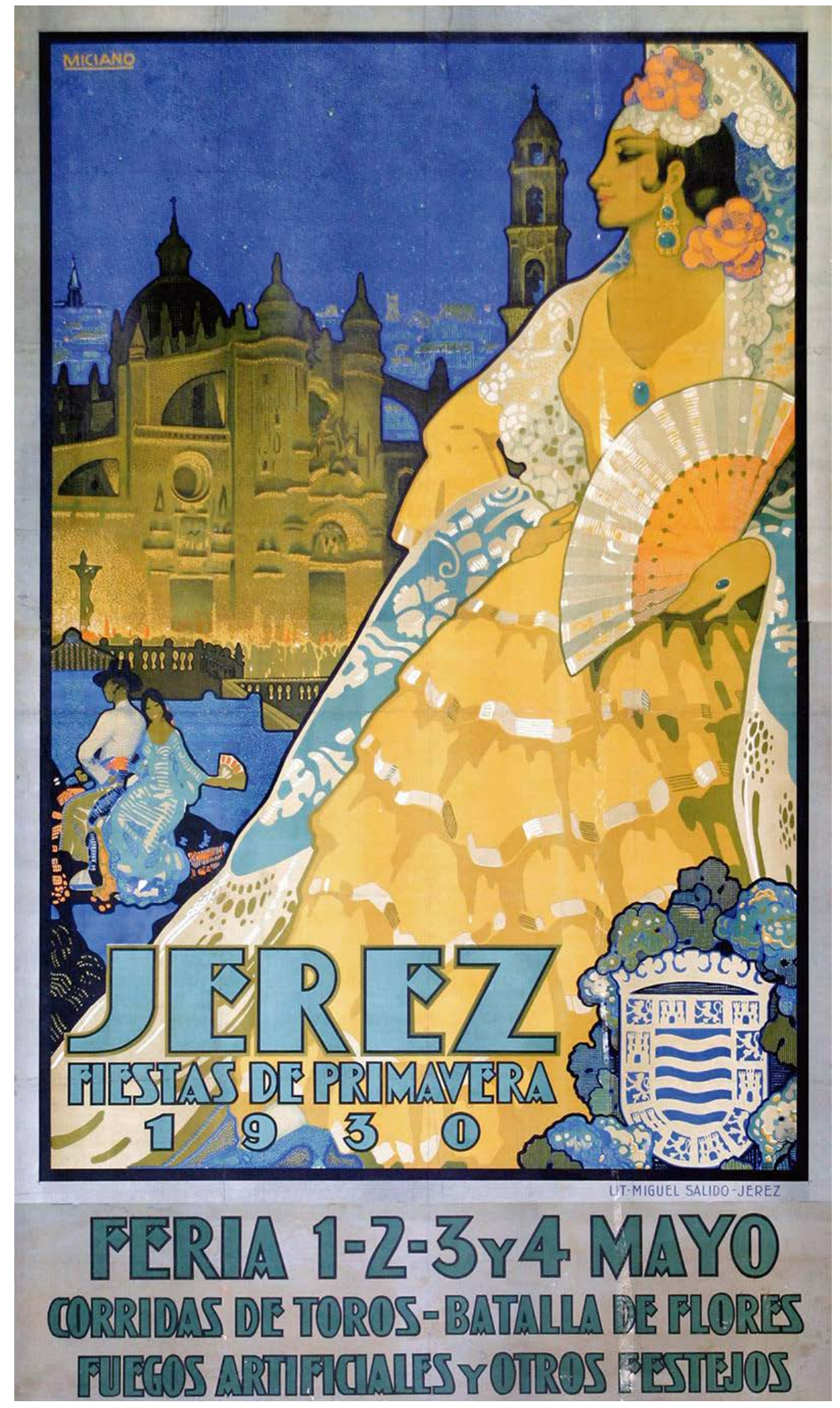

Fig. 10. Teodoro Miciano, Cartel Jerez, Fiestas de Primavera (1930). Litografía Miguel Salido, Jerez. Ayuntamiento de Jerez. 


\section{El caso Mamelón}

En la plaza Mamelón de Jerez estuvo situado el taller de José Luis Torres, dibujante de etiquetas que mencionamos antes. Es aquí donde se reúnen a iniciativa de Juan Montes Pina, sobrino de Torres, tres jóvenes que habían coincidido en los talleres litográficos de la ciudad: Manuel Valle Cortés (1932-2006), Rafael Virués de Segovia y Llamas (1932-2017) y el mencionado Juan Montes Pina (1929-2000). En torno a este grupo y la denominación «Mamelón» («Dibujos Mamelón», «Proyectos Gráficos Mamelón» o sus siglas «Pro.Gra. Ma.») se conformará un elenco de dibujantes que cubrirán décadas de creación gráfica en Jerez y su trabajo constituirá una referencia en su ámbito a nivel nacional (Jiménez, 2006).

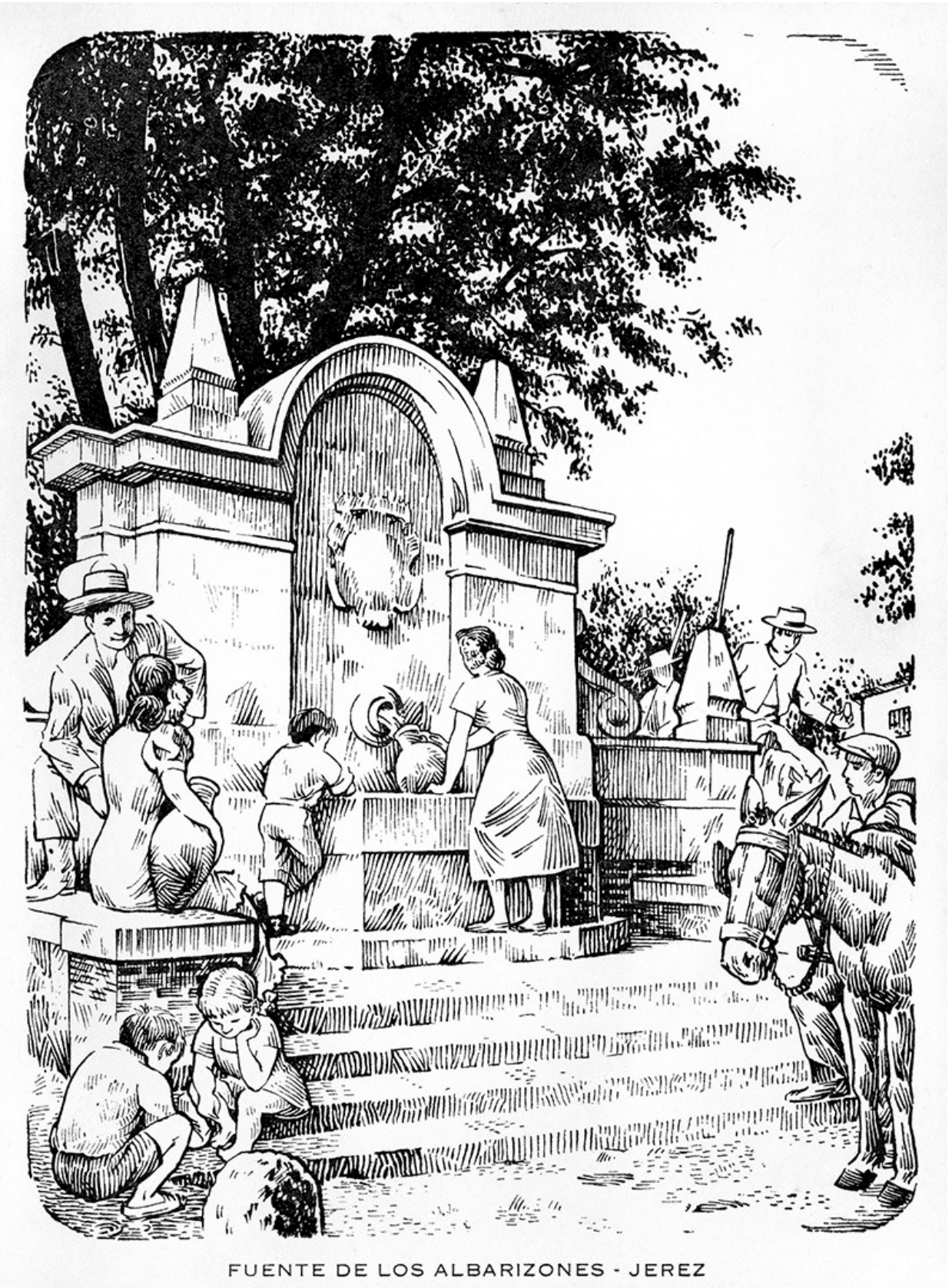

Fig. 11. Dibujos Mamelón, fuente de los Albarizones, Jerez (s/f años 50). Colección particular. 


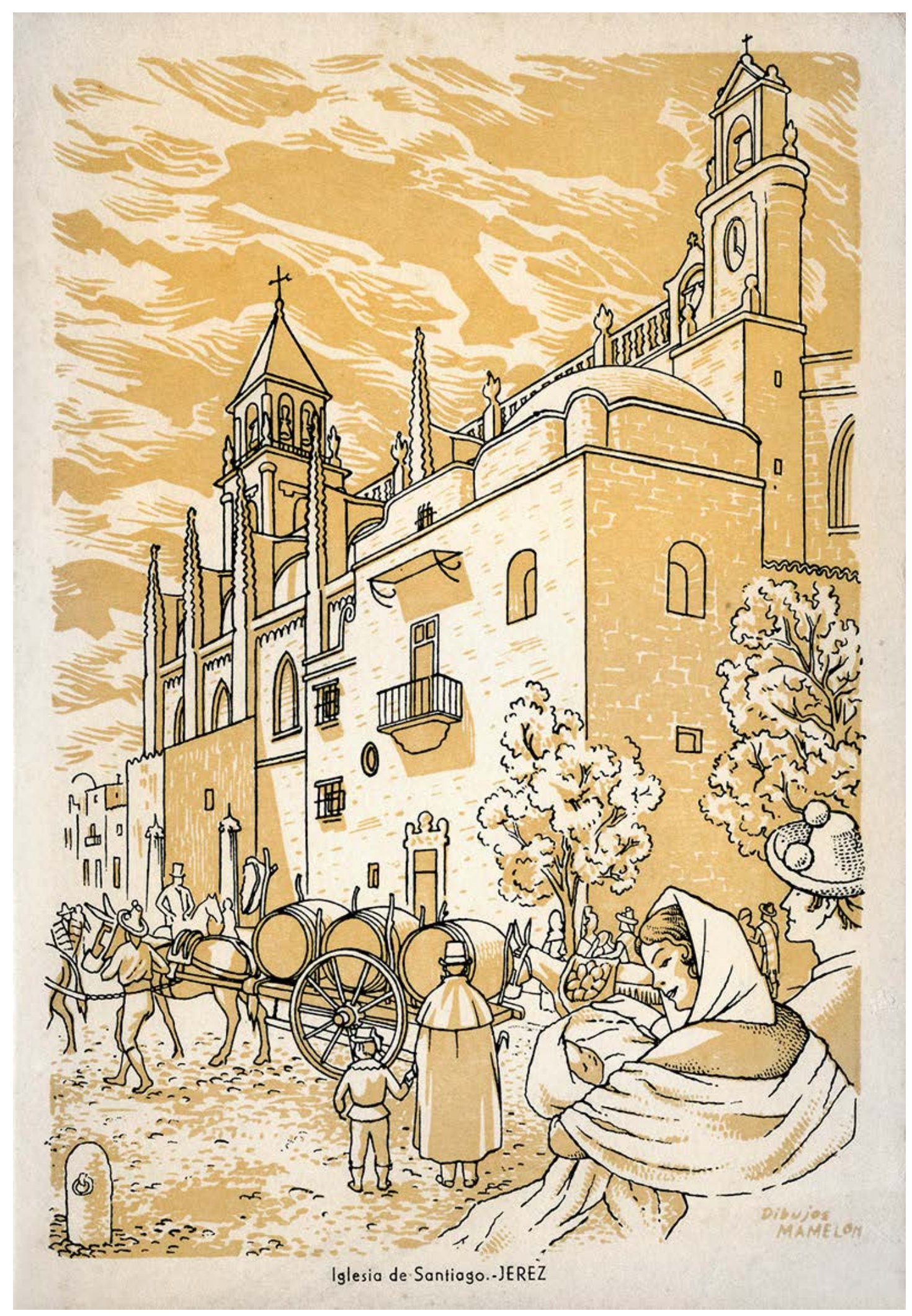

Fig. 12. Dibujos Mamelón, iglesia de Santiago, Jerez (s/f años 50). Colección particular 


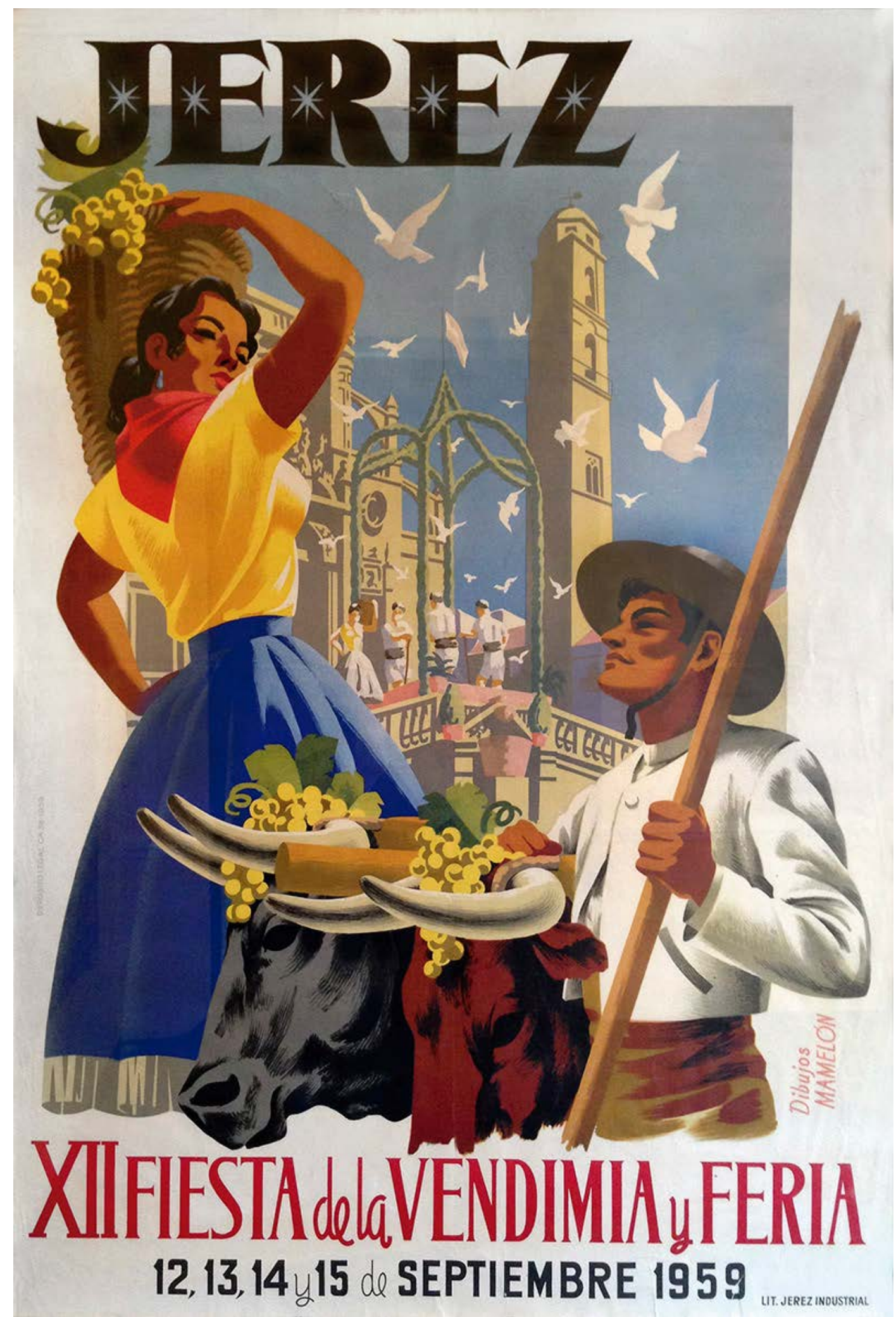

Fig. 13. Rafael Virués (firmado Dibujos Mamelón), cartel XII Fiesta de la Vendimia y Feria (1959). Litografía Jerez Industrial. Ayuntamiento de Jerez. 
Juan Montes Pina nace en 1929 y en torno a los 7 u 8 años muere su padre. Su madre, con varios hijos varones que sacar adelante, los anima a estudiar Comercio, pues ve que es una ocupación con futuro. Juan realiza estos estudios, que compatibiliza con la Escuela de Artes y Oficios, dada su inclinación al dibujo. Con catorce años se incorpora al taller de su tío José Luis, y realiza sus primeros trabajos profesionales. Posteriormente se incorpora al taller de dibujo de Jerez Industrial. Es en esta época donde realiza las ilustraciones de la $2^{\text {a }}$ edición del libro de José $\mathrm{M}^{\mathrm{a}}$ González Gordon, Jerez-Xerez, Sherish, ${ }^{3}$ en las que muestra gran destreza y maestría en el dibujo. Permanecerá en esta empresa hasta el servicio militar. A la vuelta del mismo, que realiza en Canarias y donde trabaja de forma esporádica pintando vallas murales de cines, se independiza en la calle Julio Ruiz de Alda (Ahora calle Sevilla, junto a la Plaza del Mamelón). A principios de los cincuenta, con entusiasmo e iniciativa, consigue reunir a un grupo dibujantes que, como él, habían pasado por los talleres de impresión de Jerez Industrial en torno a la denominación «Dibujos Mamelón». En este grupo están además de los mencionados Valle y Virués, Sebastián Moya González 'Cachirulo', Gonzalo Aguilar Robles o José Franco Ortega (Pérez y Jiménez, 2007). Sus clientes son los propios talleres litográficos y de impresión, como Jerez Industrial o Jerez Gráfico, y realizan encargos para las principales bodegas, como Lustau, González Byass, Domecq, Osborne, Caballero y Valdespino. En 1963, el director del grupo empresarial Jerez Industrial, Antonio Salido Paz, les propone la dedicación en exclusiva del estudio a las demanda de sus talleres. Es una buena oferta, en la medida que supone la capitalización e inversión en un proyecto ambicioso para un grupo industrial clave en Jerez, pero les compromete su libertad de movimientos para dedicarse a nuevos clientes. De esta forma se constituye «Proyectos Gráficos Mamelón» (o «Pro.Gra.Ma.») el 26 de marzo de 1963, ${ }^{4}$ que se establece en la calle Arcos, 14. Tres años más tarde, en 1966, se trasladan a un nuevo domicilio en calle Pizarro, 9. En esta sede, el estudio se amplía, y además de los espacios dedicados al dibujo, se mejoran las instalaciones con un taller de fotografía y fotomecánica.

Manuel Valle Cortés nace en Sanlúcar de Barrameda en 1932, y su familia se traslada a Jerez cuando tiene dos años de edad. Su abuelo Gabriel Cortés, litógrafo que se había trasladado desde Valencia al reclamo de las imprentas que se instalaban en Jerez, entra a trabajar en los talleres de la Litografía Hurtado, y es él quien lo introduce en la afición por el dibujo y la caligrafía, que se ve reforzada por las habilidades de su madre, Aurelia Cortés, que había estudiado en la Escuela de Artes y Oficios. Los cuadernos escolares de Manuel están llenos de dibujos, con personajes de todo tipo. Su socio Rafael Virués, compañero en la escuela, recordaba cuanto le debía a la capacidad de observación de Manolo Valle. Con catorce años, se incorpora como aprendiz en Jerez Industrial y, poco después, a Industrias Gráficas Orla. Aquí aprende las técnicas fotomecánicas y su aplicación al offset, que empieza a introducirse en los talleres. Junto con Juan Montes y Rafael Virués, se reúnen en el grupo iniciador de "Mamelón», y empieza una trayectoria creativa que los mantendrá unidos durante su vida profesional. Esta experiencia quizás por lo poco frecuente en Andalucía y menos en estos años, se configura por el reparto de tareas en el grupo y por la personalidad de sus integrantes. El carácter de Manuel Valle es especialmente tranquilo, amable, tímido, paciente, poco propenso a tratar con clientes, pero concentrado en su trabajo: meticuloso, observador, y de una destreza técnica que le hace dibujar las escenas más diversas sin casi necesidad de apuntes previos, con rasgos precisos y limpios. Sus figuras femeninas son características por su expresión, entre dulce y plácida, sus grandes ojos y sus delgadas cinturas. Quizás

3 De este libro se hicieron sucesivas ediciones (1935, 1948, 1970...), siendo las más antiguas de gran de interés para los bibliófilos. 
el diseño de la vidriera de la escalera del Consejo Regulador de vinos de Jerez y Manzanilla de Sanlúcar es su muestra más clara, junto con infinidad de ilustraciones para etiquetas. Otra de sus realizaciones, que terminaron convirtiéndose en imagen icónica de una empresa, fue la del arrumbador de Valdespino, plasmada en la silueta de la veleta de dicha bodega. La preocupación por la autoría de los proyectos que salen del estudio tampoco es preocupación para Manuel ${ }^{5}$ —ni el resto de los integrantes- pues es algo no valorado, como tampoco se le otorga a los originales —artes finales de factura impecable, en su mayoría perdidos-que salen de los tableros de dibujo. Quizás la anécdota que retrate a Manolo Valle y que más recuerdan quienes trabajaron con él era la disposición casi obsesiva de las colillas en su cenicero: perfectamente ordenadas en un orden establecido y que él mantenía durante sus sesiones de trabajo, enfundado en su bata y concentrado sobre su escritorio.
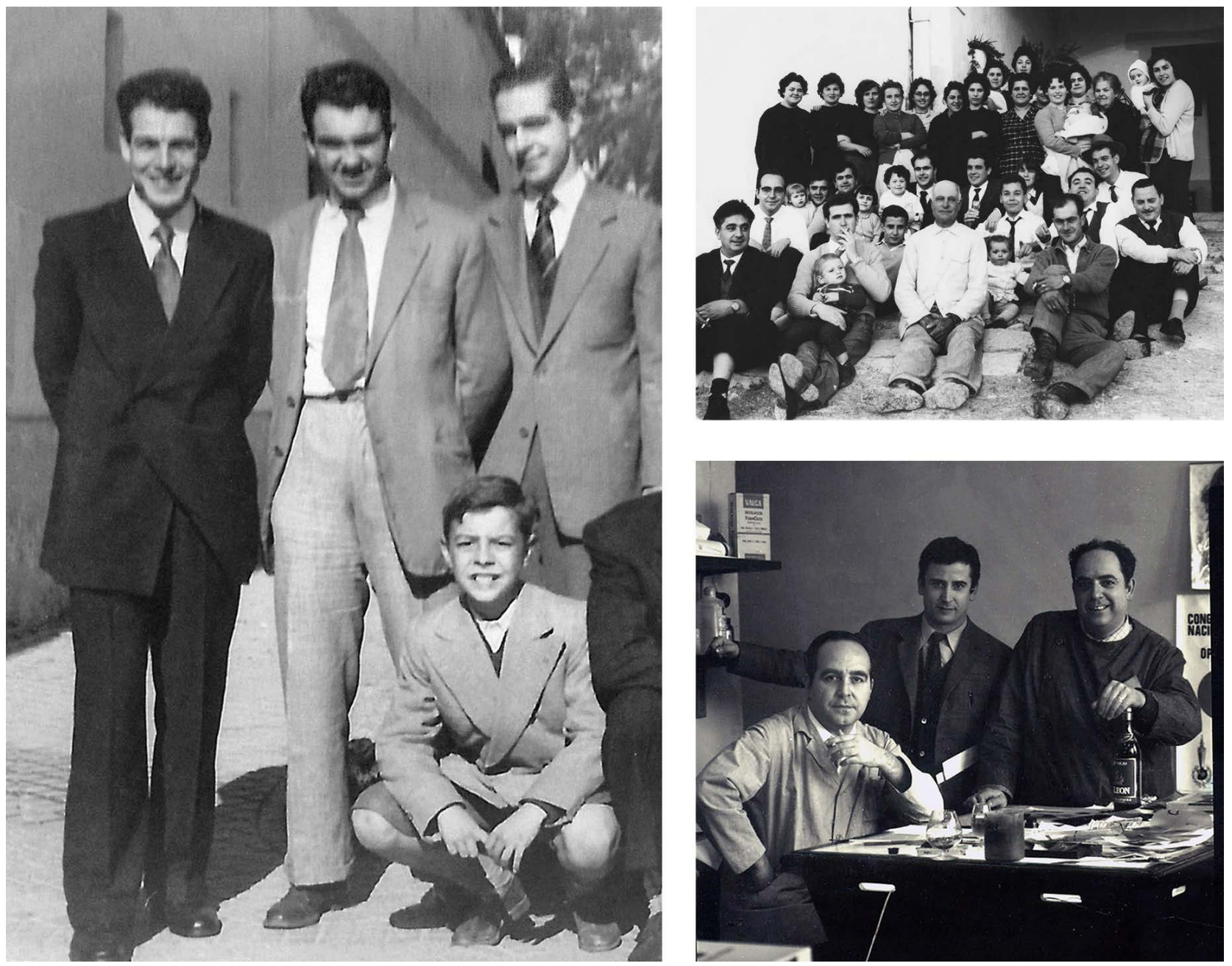

Fig. 14. Juan Montes Pina, Rafael Virués y Manuel Valle, (s/f, años 50). Archivo Manuel Cervera.

Fig. 15. Reunión de familiares y amigos de los trabajadores de Mamelón (s/f). Archivo familia Manuel Valle

Fig. 16. Manuel Valle, Juan Herrador y Manuel Rodríguez, en el estudio (s/f, años 50). Archivo familia Manuel Valle.

Rafael Virués de Segovia y Llamas nace en Jerez en 1932. Compañero de Manuel Valle durante su etapa

5 Según su hijo, «...él siempre decía que eso no tenía importancia, que para él había sido una suerte continuar con la tradición de su abuelo y su madre. Él se sentía un privilegiado de haber podido vivir toda la evolución de la publicidad del siglo XX aquí, en Jerez». (Simó, 2015). 
escolar, asiste a la Escuela de Artes y Oficios, entrando de aprendiz de litografía en el taller de Jerez Industrial para trabajar posteriormente en Litografía Hurtado. Integrado en el grupo de «Dibujos Mamelón», su tarea se centra en las fases creativas. De esta época es el cartel de la Fiesta de la Vendimia de Jerez de 1959, así como otros de temas diversos, donde muestra una gran maestría. Es el único de los tres iniciadores de Mamelón que pude conocer en persona. Fallece el 1 de enero de 2017.
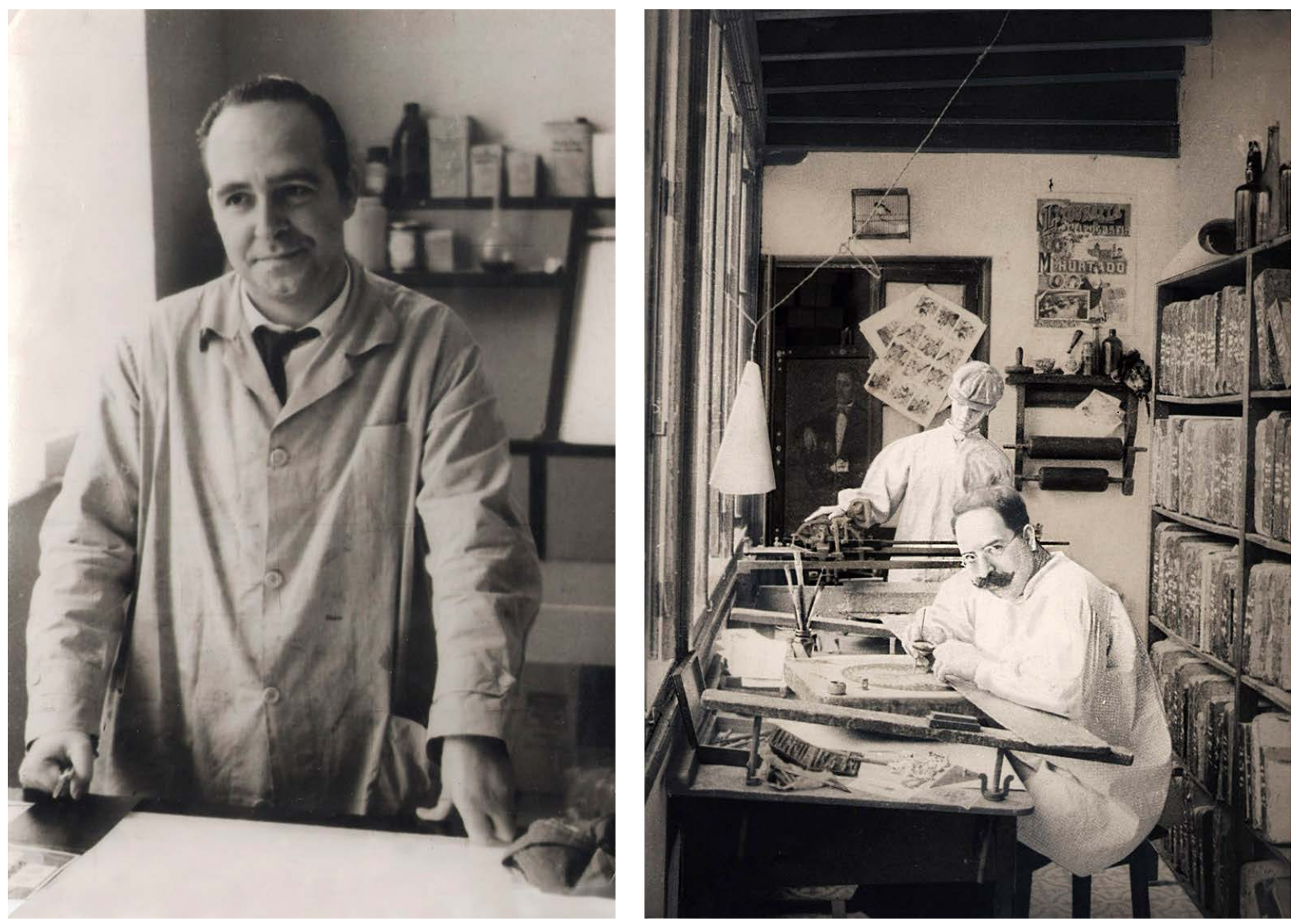

Fig. 17. Manuel Valle en el estudio (s/f, años 50). Archivo familia Manuel Valle.

Fig. 18. Fotografía de recreación de un taller litográfico.

Aparecen, caracterizados, Manuel Rodríguez Gómez y Antonio Panal Iglesias (1963). Archivo familia Juan Montes.

Por «Pro.Gra.Ma» pasaron muchos creativos, entre los que destacan, además de los tres promotores mencionados, Gonzalo Aguilar Robles, Pedro Carabante Medina 'Peri', Manuel Cervera Pérez, Antonio Curtido Mora, Manuel García Díaz, Juan Herrador Granero, Antonio Higuero Domínguez, Sebastián Moya González 'Cachirulo', Enrique de Porras, Juan Luis Rojas Fernández, Joaquín Rubiales, Juan Ruiz, José María Sánchez Escámez y Juan Miguel Quirós. En el taller de fotomecánica participaron Manuel Aguilar Robles, Ana María González, Blas Gabriel Lloret Benítez, Antonio Panal Iglesias, Manuel Rodríguez Gómez y Eugenio Sánchez González. En la administración Manuel Gómez Pina, primo de Juan Montes, y Mª̣ del Mar Aguilar. La sociedad se disuelve en 1988, y Jerez Industrial sale del accionariado. Algunos de sus integrantes, entre ellos Manolo Valle, Manuel Gómez, José Romero y Blas Lloret, constituyen Mamelón SAL (sociedad anónima laboral), que sobrevive algunos años, pero sin el dinamismo de épocas precedentes. Otros integrantes, como, 
Pedro Carabante, Juan Herrador y Gabriel González crean Frontera Publicidad, en calle Pedro Alonso, que se orientará especialmente a la emergente actividad publicitaria en medios. De forma independiente, los iniciales integrantes de Mamelón, Juan Montes y Rafael Virués realizan trabajos esporádicos, hasta su jubilación definitiva.

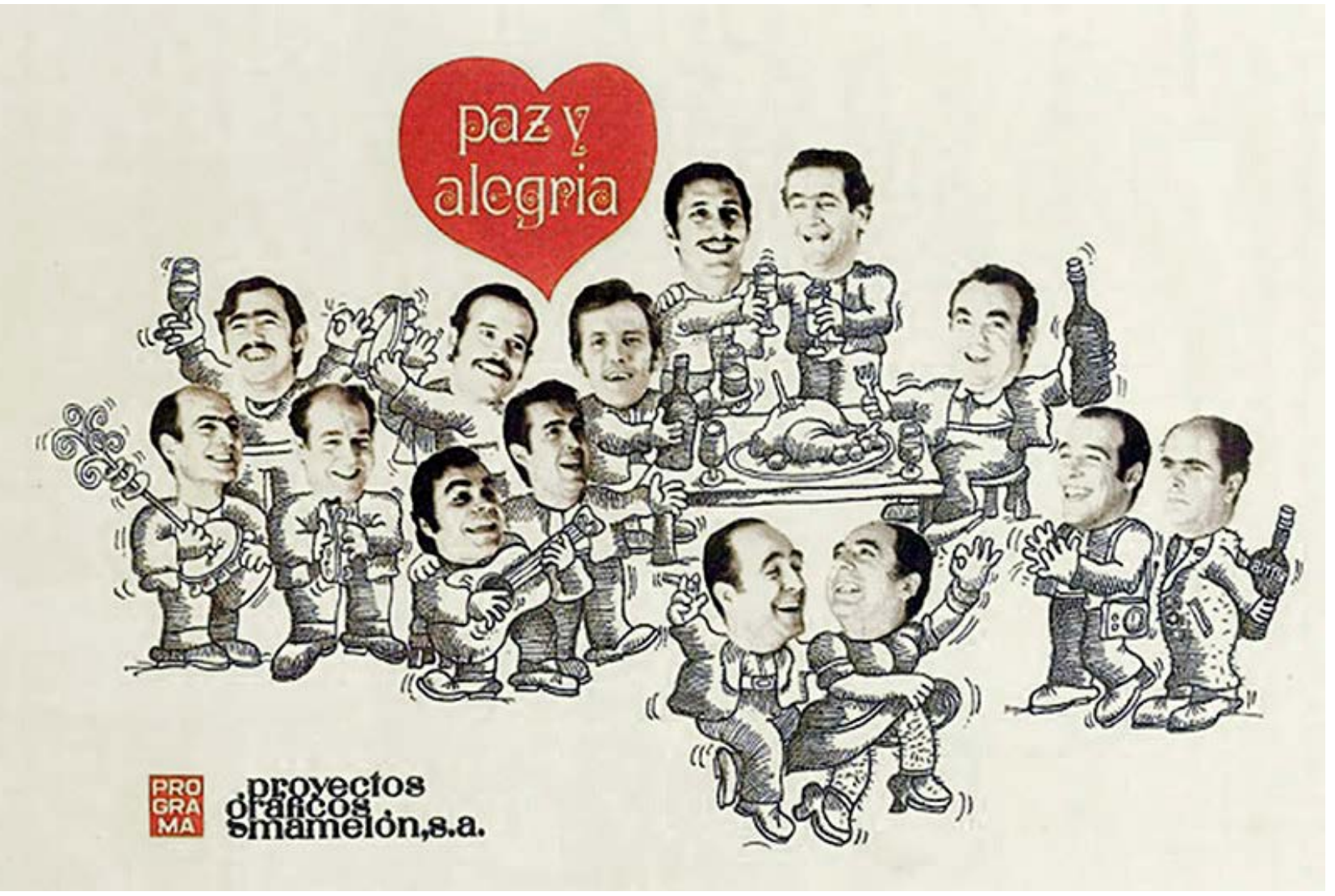

Fig. 19. Felicitación navideña de ProGraMa (s/f). Archivo familia Manuel Valle.

Especialmente interesante es la experiencia de Sebastián Moya González, conocido por su sobrenombre de 'Cachirulo' y con el que ha firmado infinidad de trabajos. Nace en Jerez en 1930, de espíritu inquieto, estudia en la Escuela de Artes y Oficios. Trabaja en la empresa de Justo Lara, 'Ponito', haciendo originales para productos promocionales. Se incorpora a Jerez Industrial en el taller litográfico, en la realización de carteles y etiquetas. Allí conoce el trabajo sobre piedra, tanto con lápiz litográfico, como con plumilla y buril. De forma independiente, Sebastián también trabaja con su amigo José Benítez Troya, diseñador que posteriormente desarrollaría una interesante carrera en París, Bélgica y Holanda, en la trastienda del bar La Fábrica, donde comparten estudio con 'Buchito', un viejo mendigo también artista. Pasa por «Dibujos Mamelón» en su primera etapa, y son de esta época sus carteles del Corpus en Cádiz de 1958, en litografía, o los de las «Fiestas típicas gaditanas» de 1958 y 1959 - llamadas así al estar prohibida la tradicional denominación de 'carnaval'-, así como cubiertas de libros y trabajos diversos. En estas obras es donde destaca por sus dotes para la caricatura, en la sintetización de los rasgos de personajes de marcada expresividad y desenfadado incluso en temas solemnes. A través de una oferta de amigos, intenta emigrar a Venezuela, situación que no 
consigue $^{6}$ traslandándose poco después a Brasil, donde sí es admitido. Trabaja como ilustrador para medios publicitarios, en el Diario O Globo de São Paulo y habitualmente publica caricaturas en la revista Visão, de la misma ciudad. Tras tres años de experiencia americana, decide volver a la península, en principio a Madrid, donde trabaja para las agencias Clarín y Alas. Posteriormente marcha a Jerez y se integra en el equipo de Frontera Publicidad, empresa formada por antiguos compañeros de Mamelón, donde se jubila en 1995. Nunca dejó de realizar caricaturas, muchas de ellas realizadas para publicaciones de amigos.

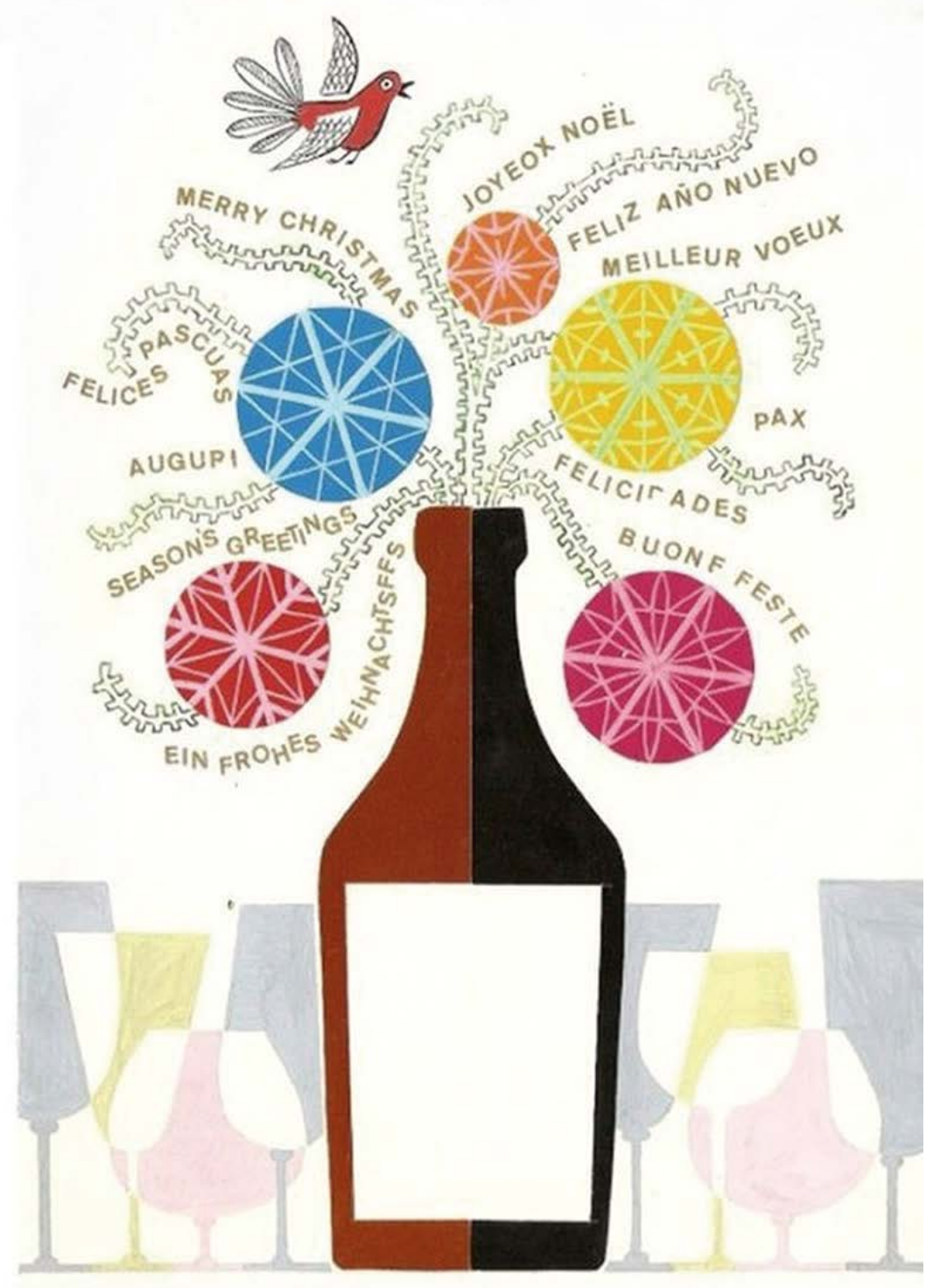

Fig. 20. Felicitación navideña de ProGraMa (s/f). Archivo familia Manuel Valle.

6 Como ocurría en la mili, Sebastián cuenta que por entonces en Venezuela no admitían emigrantes de baja estatura, y dado que la suya no cumplía los requisitos por dos centímetros, tuvo que desistir. 

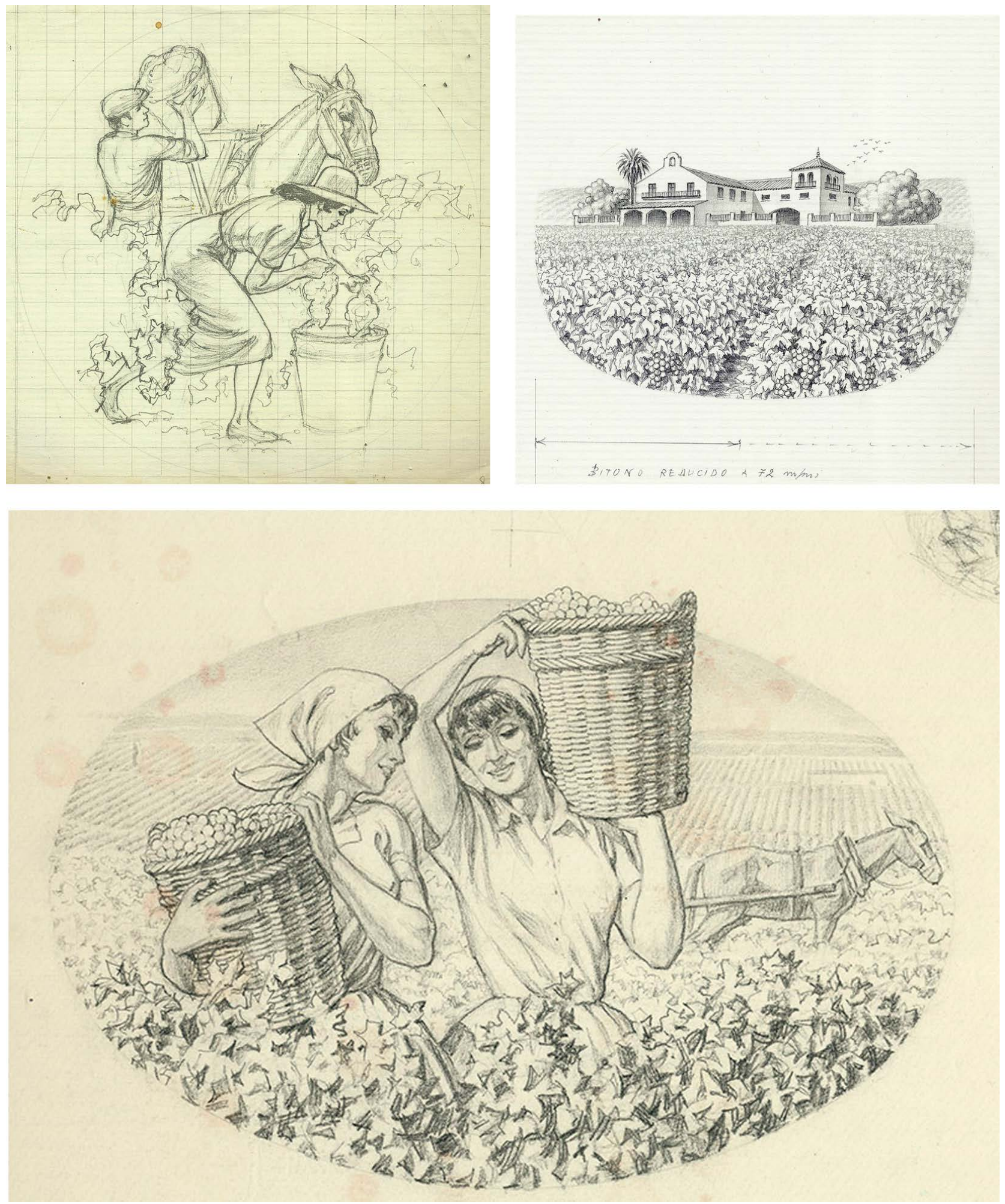

Fig. 21, 22 y 23. Manuel Valle, bocetos de etiquetas (s/f). Archivo familia Manuel Valle 

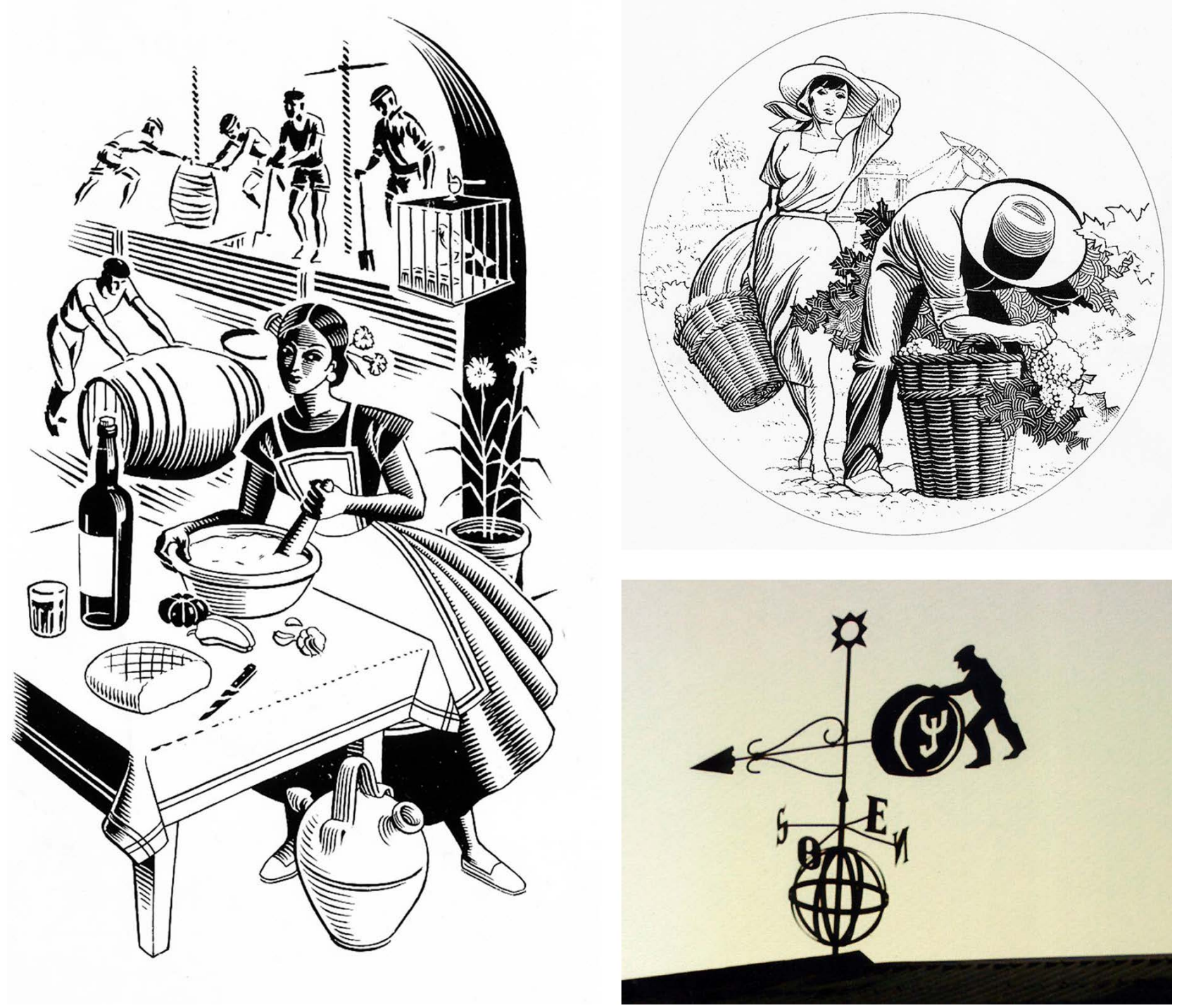

Fig. 24 y 25. Manuel Valle, bocetos de etiquetas (s/f). Archivo familia Manuel Valle.

Fig. 26. Manuel Valle, arrumbador en la veleta en Valdespino (s/f). Archivo familia Manuel Valle.

\section{La transformación de los noventa}

Junto con las personas que hemos citado, existieron más profesionales que desarrollan su labor en el mismo ámbito físico y temporal. Este artículo no pretende ser un estudio exhaustivo, sino un acercamiento a una forma de concebir y ejecutar la creación gráfica cuando era una profesión reducida y circunscrita a unas necesidades concretas. La experiencia de Mamelón, y los dibujantes de su entorno y en sus distintas etapas, es significativa en la medida que retrata un ejemplo de actividad profesional, que ni es el modelo de estudio de diseño que se articulará en las décadas posteriores ni el de agencia de publicidad del siglo XX. Su estructura parte de un modelo específico que es el que necesita la industria gráfica jerezana, que es la principal canalizadora de los encargos de la industria vinatera. 
Y quizás por esta peculiaridad se producen las dos circunstancias que hacen a este colectivo singular: proceden de una tradición continuada en el tiempo, que sobrevive a sucesivas crisis pero de las que surge reinventado. Este hecho se manifiesta tanto en la industria que le da origen como en la misma industria gráfica y creativa. Con la transformación del mercado del vino en los años noventa, el fenómeno de la globalización y la desaparición de fronteras comerciales, los cambios en las técnicas promocionales y el impacto tecnológico, unidos a otros factores de carácter humano, así como la inexistencia de un relevo generacional, que -a nuestro entender- se produce el fin de esta trayectoria.

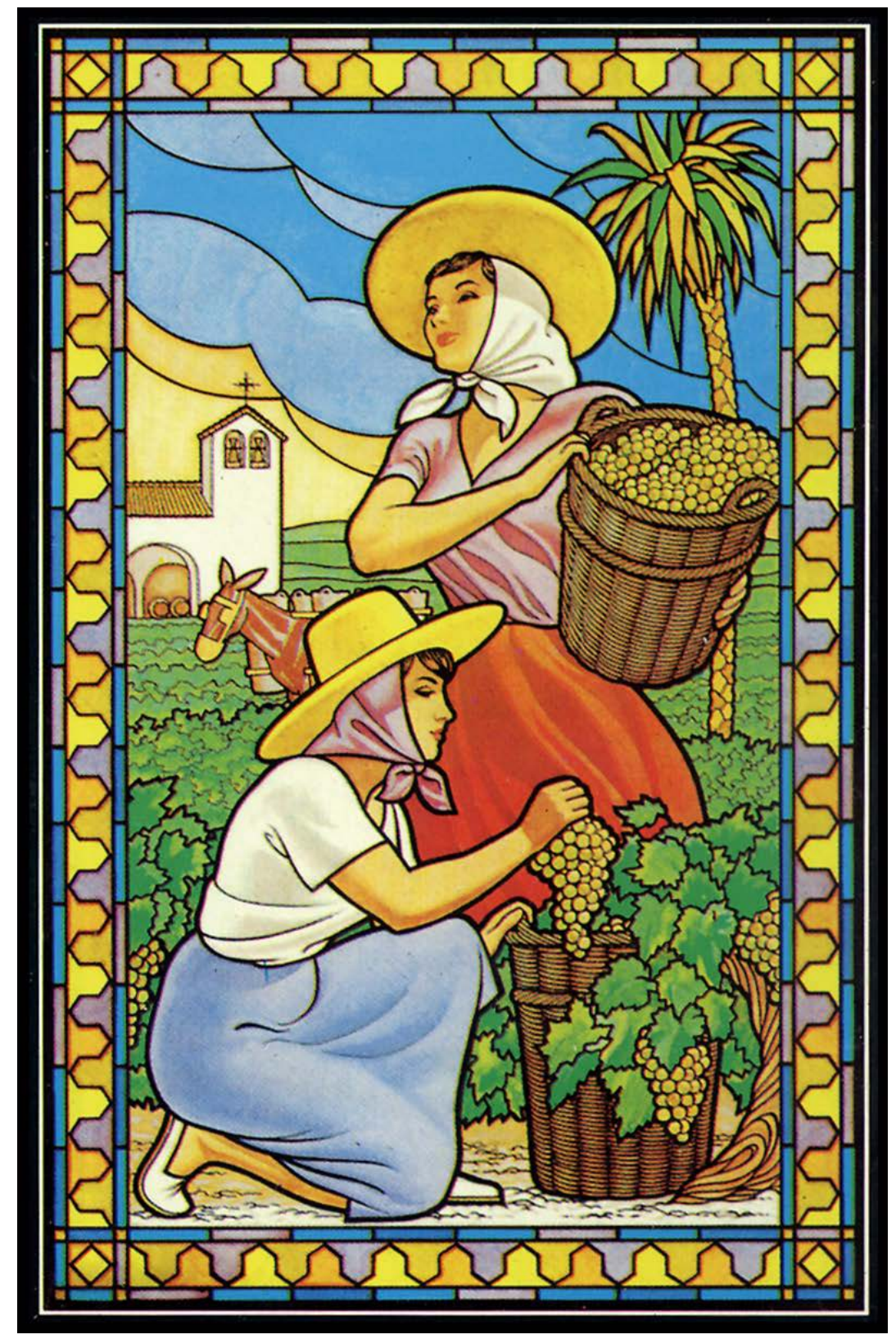

Fig. 27. Manuel Valle, vidriera del Consejo Regulador del vino de Jerez (s/f). Archivo familia Manuel Valle. 


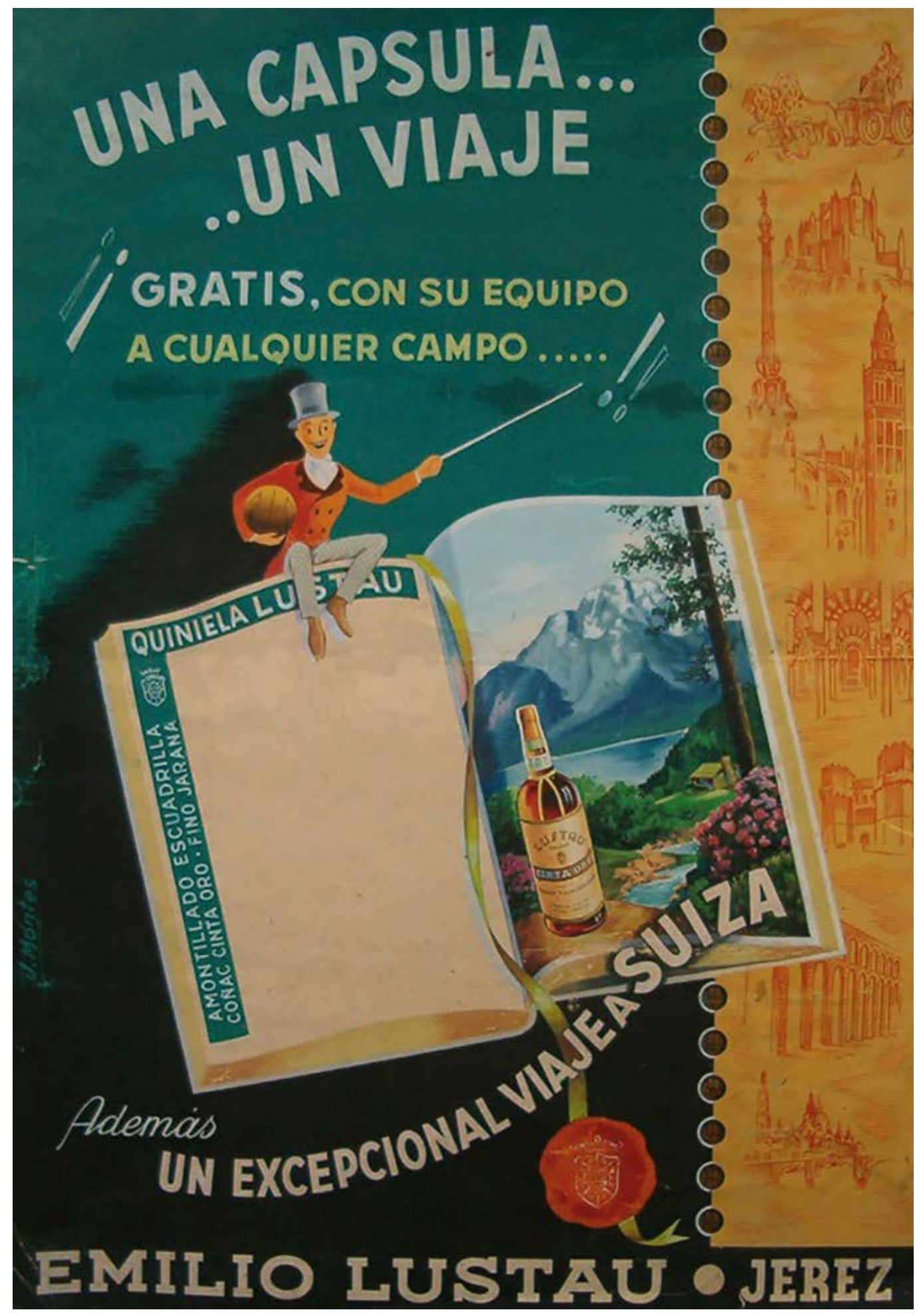

Fig. 28. ProGraMa, cartel Emilio Lustau, Jerez (s/f). Archivo familia Juan Montes. 


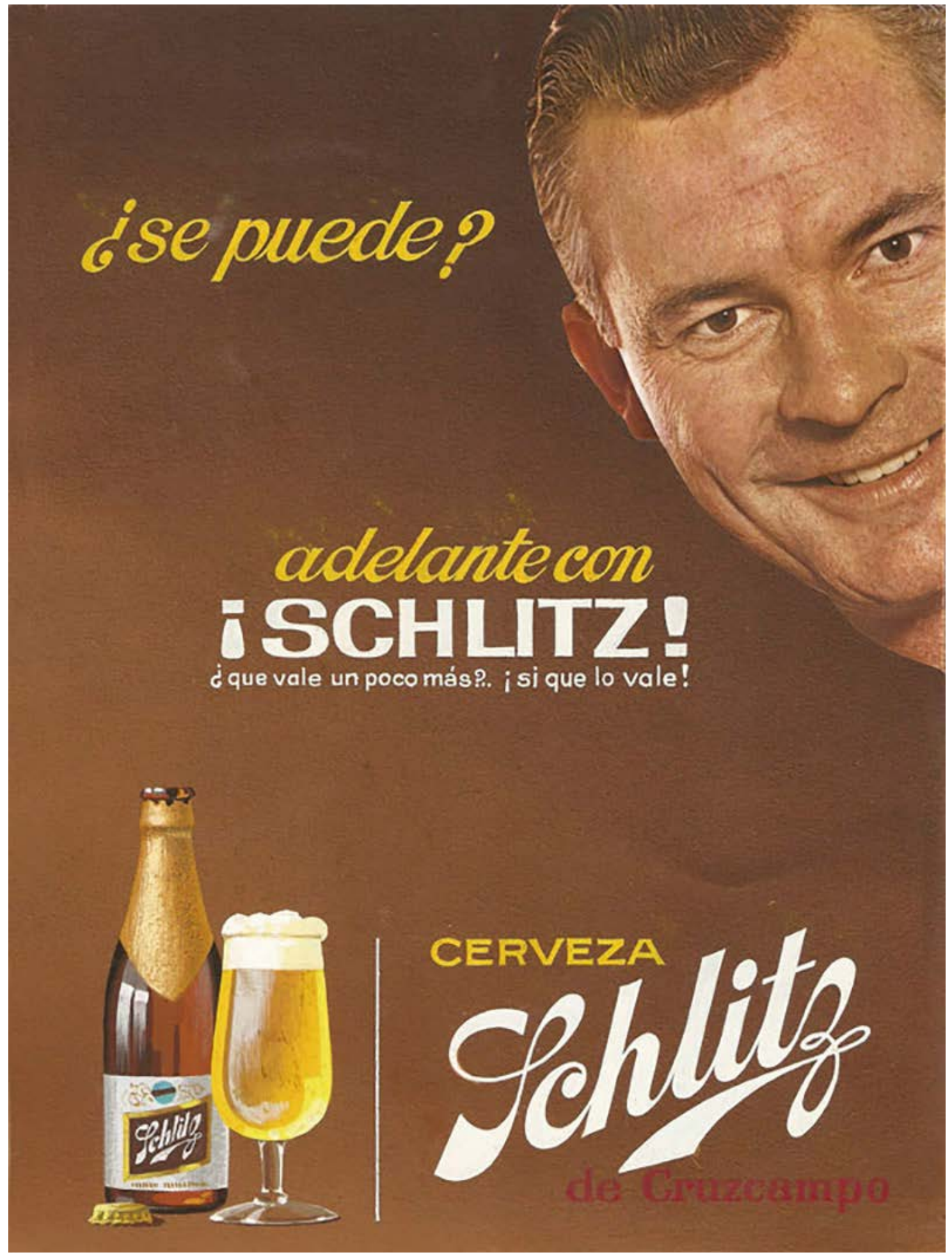

Fig. 29. ProGraMa, cartel cerveza Schlitz, Cruzcampo, Sevilla (s/f). Archivo familia Juan Montes. 

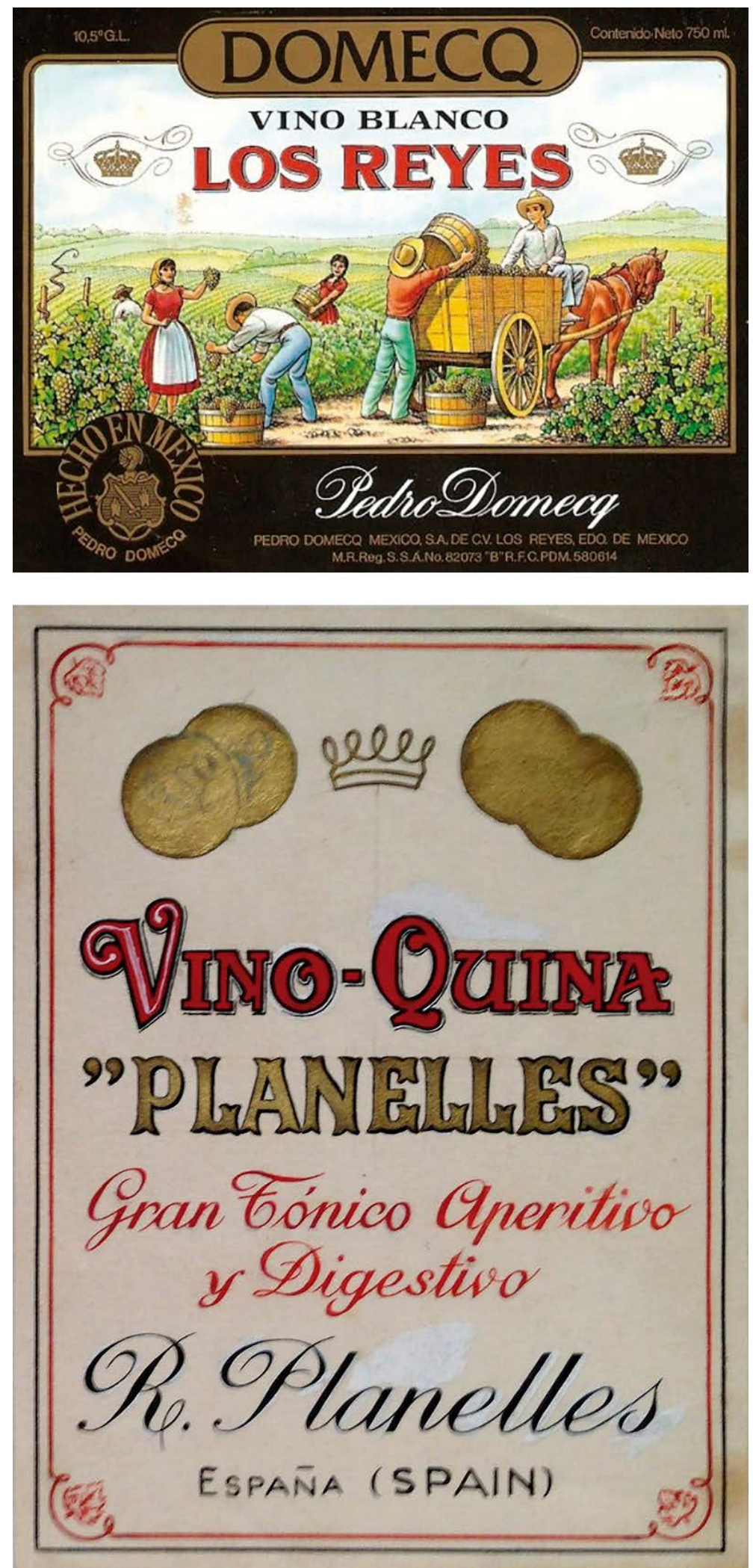

Fig. 30. ProGraMa, etiqueta vino «Los Reyes» Pedro Domecq, México (s/f). Archivo familia Juan Montes.

Fig. 31. ProGraMa, boceto de presentación etiqueta vino-quina «Planelles», España (s/f). Archivo Manuel Cervera. 

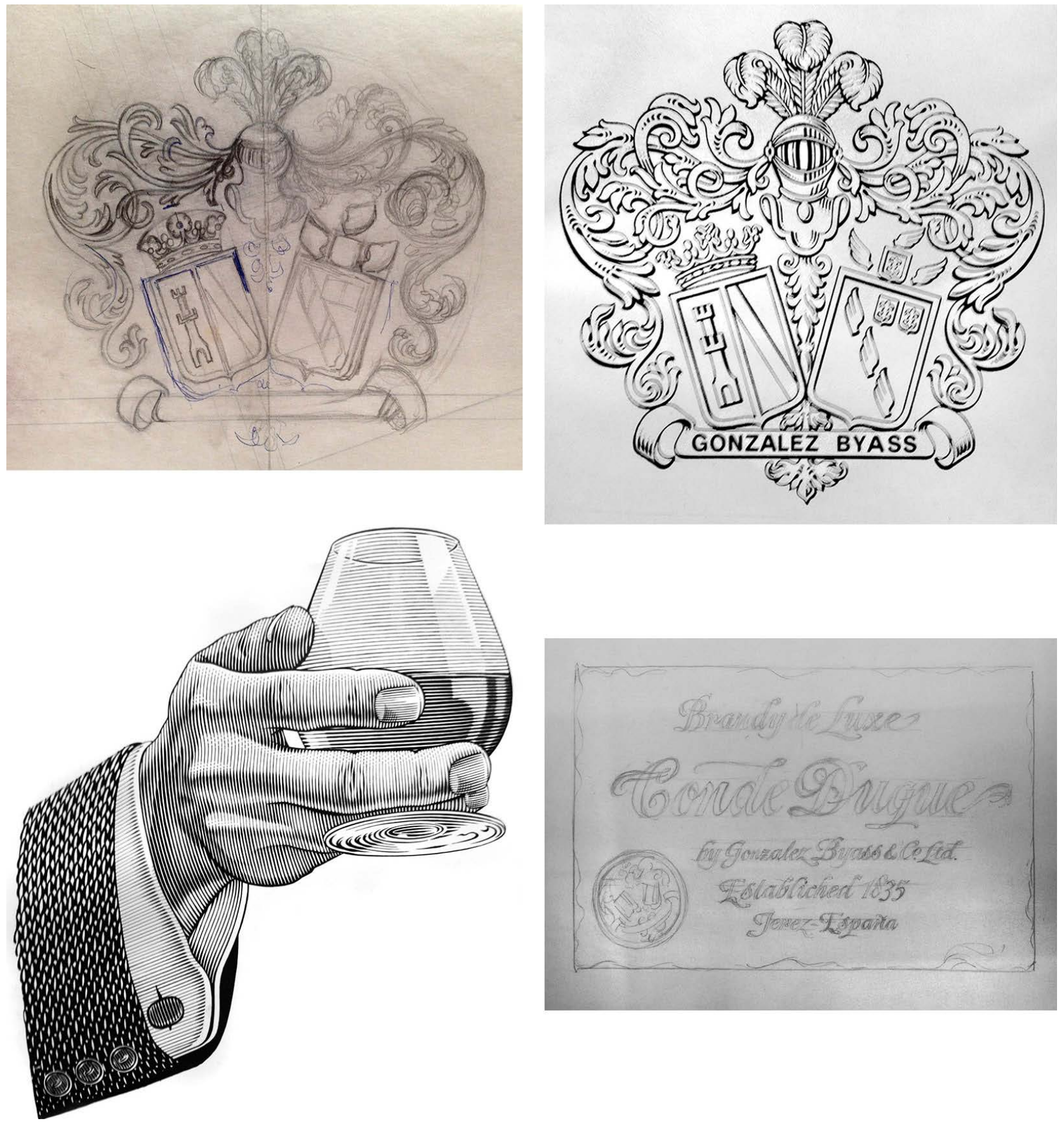

Fig. 32. Manuel Cervera, boceto a lápiz para etiqueta (s/f). Archivo Manuel Cervera.

Fig. 33. Manuel Cervera, arte final para etiqueta (s/f). Archivo Manuel Cervera.

Fig. 34. Manuel Cervera, arte final para publicidad en prensa (s/f). Archivo Manuel Cervera.

Fig. 35. Manuel Cervera, boceto a lápiz para etiqueta (s/f). Archivo Manuel Cervera. 


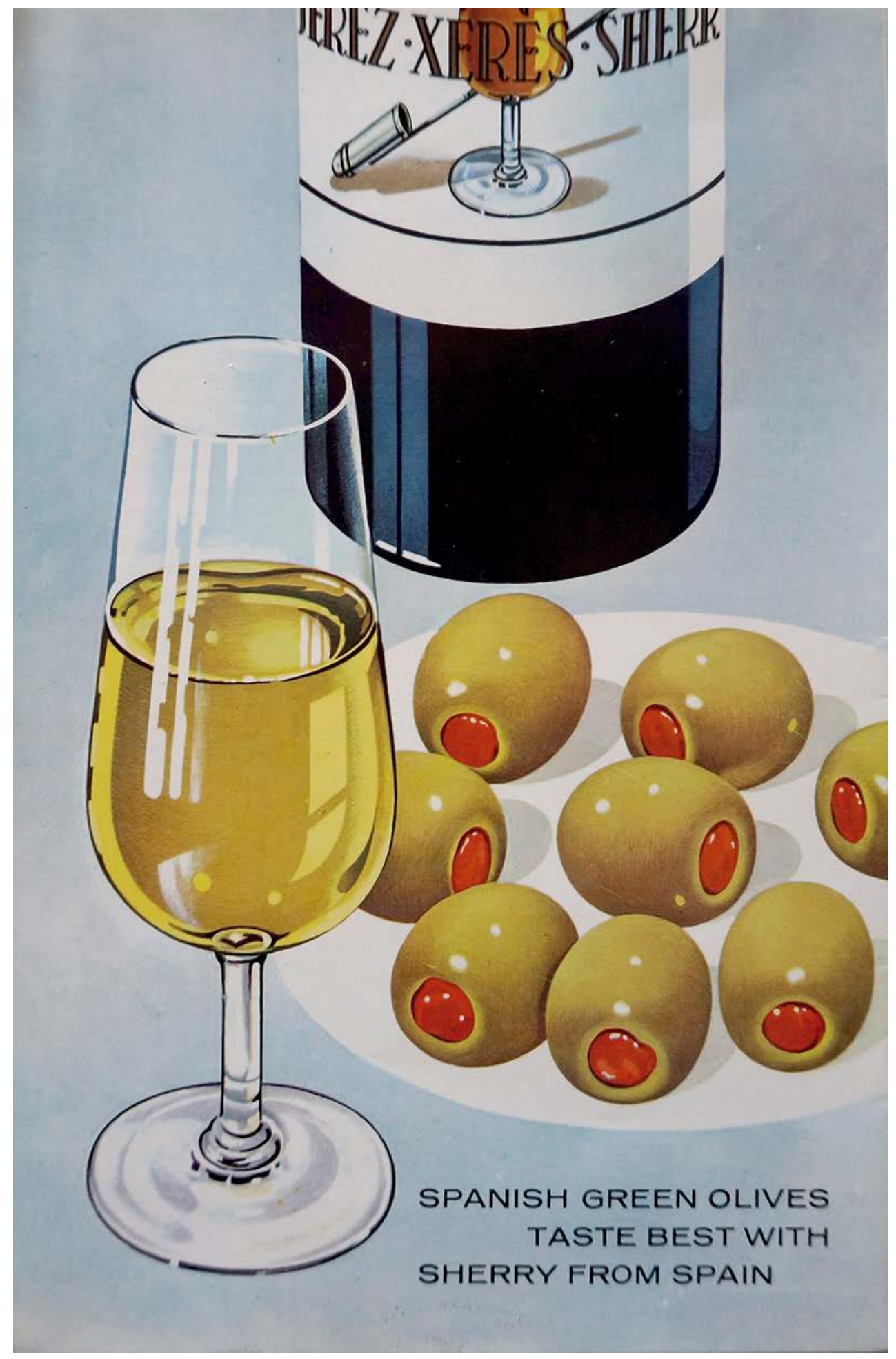

Fig. 36. ProGraMa, boceto de presentación publicidad (s/f). Archivo familia Rafael Virués. 


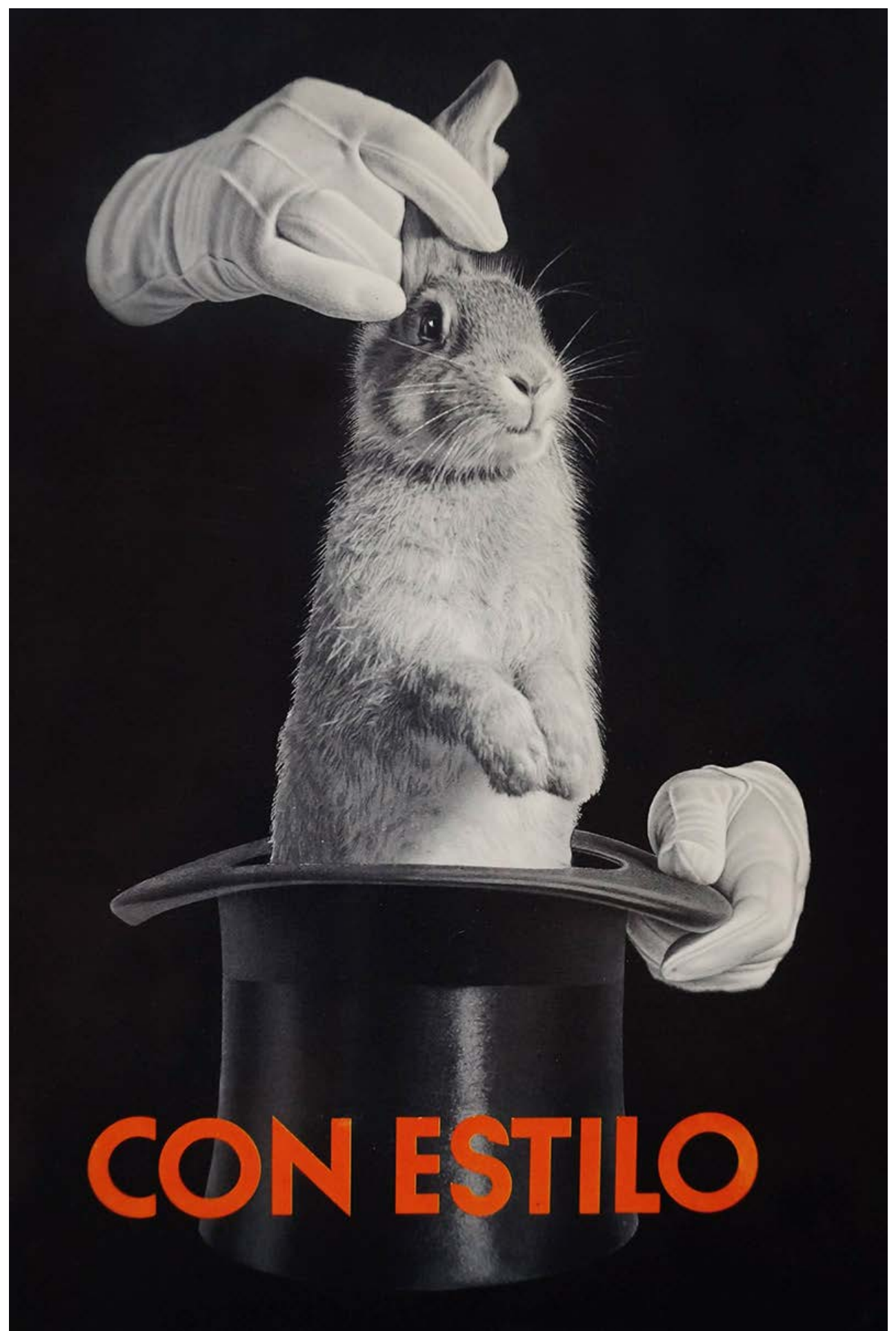

Fig. 37. ProGraMa, boceto de presentación publicidad (s/f). Archivo familia Rafael Virués. 

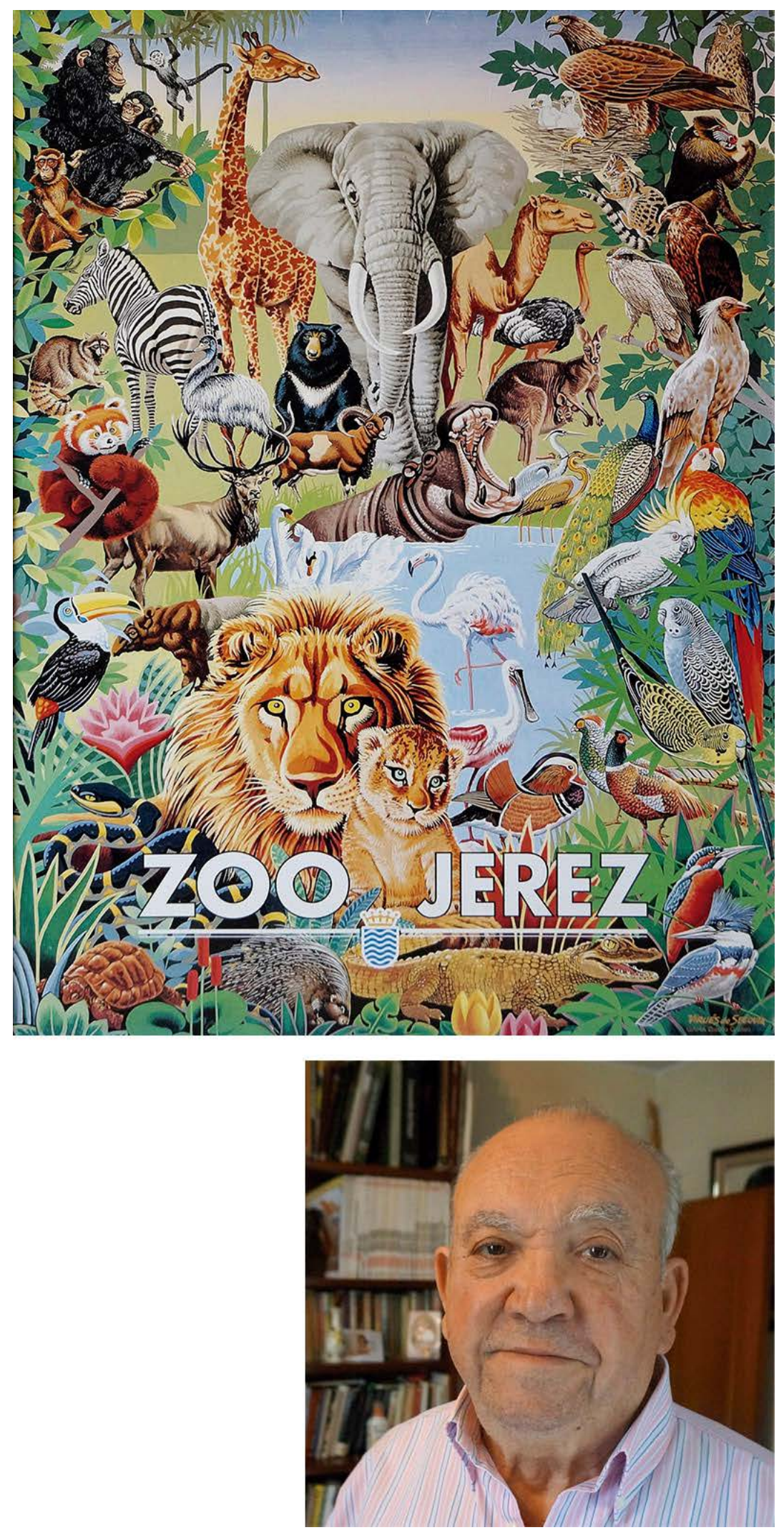

Fig. 38. Rafael Virués, cartel para el Zoo de Jerez (s/f). Gama diseño gráfico, Jerez. Archivo familia Rafael Virués.

Fig. 39. Rafael Virués, en 2013. Foto del autor. 


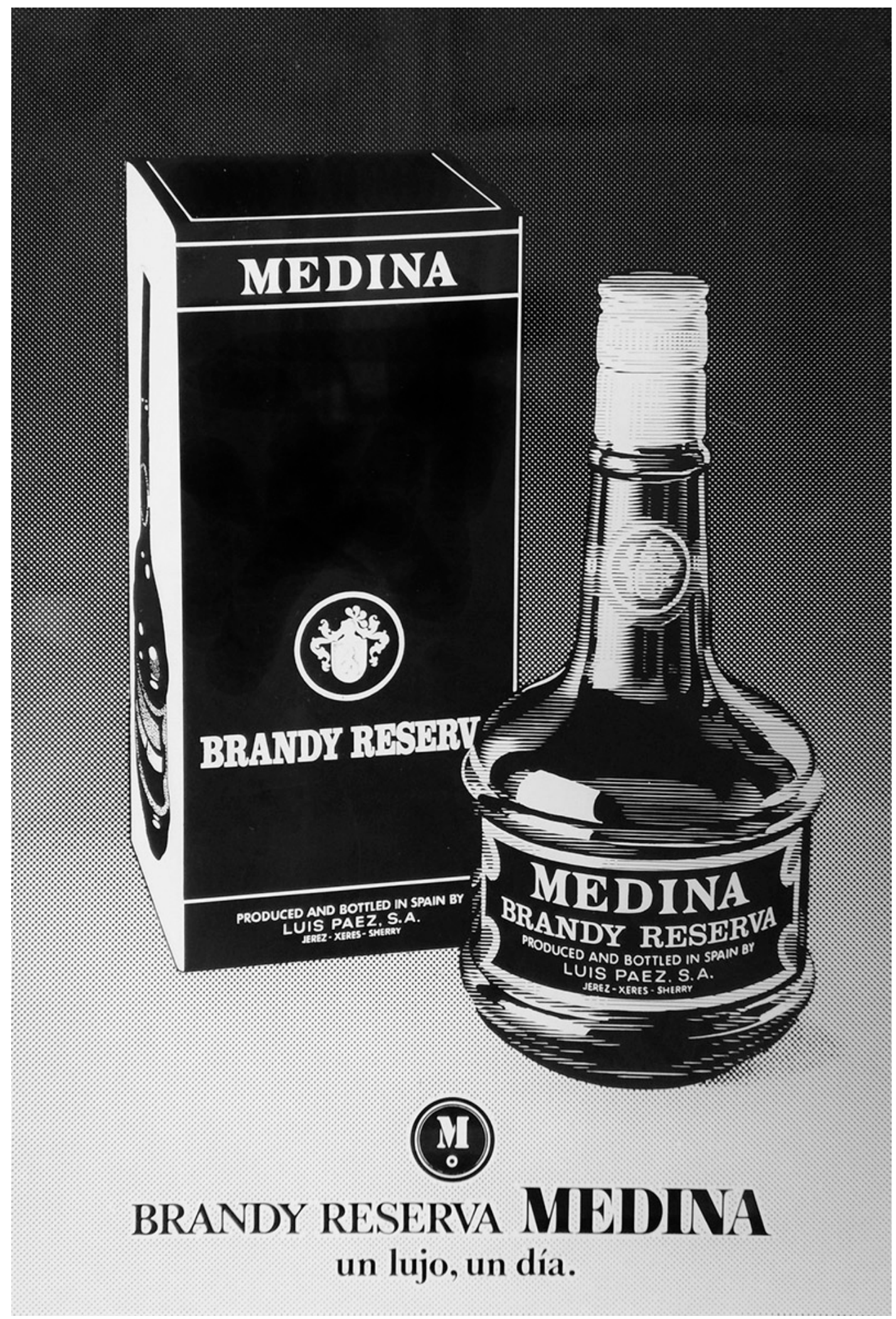

Fig. 40. Juan Herrador, arte final de anuncio en prensa «Brandy Medina», Luis Páez, Jerez (1981). Archivo Juan Herrador. ProGraMa, boceto de presentación publicidad (s/f). Archivo familia Rafael Virués. 


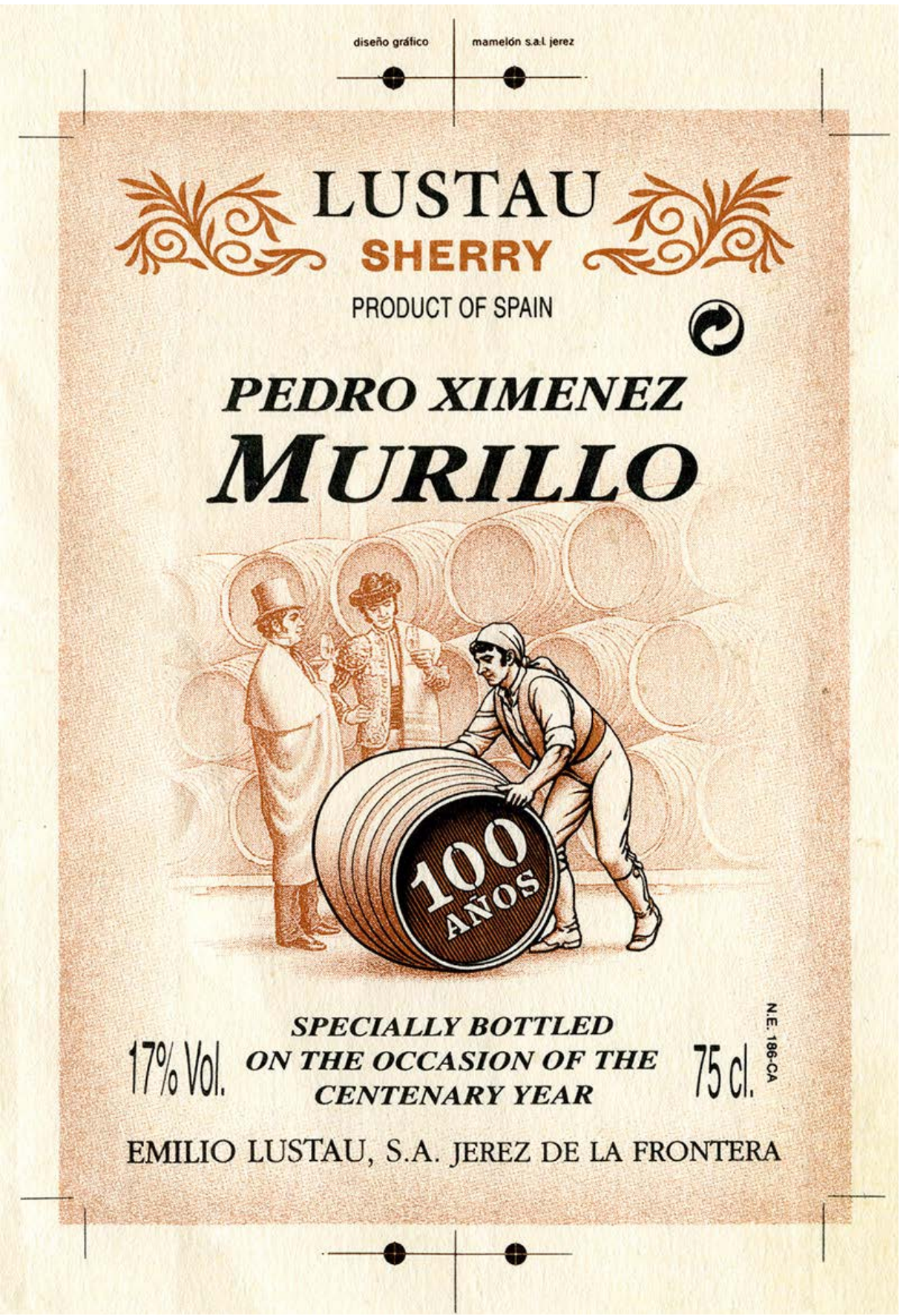

Fig. 41. Programa SAL, prueba de fotomecánica de etiqueta «Pedro Ximénez Murillo» para Lustau, Jerez (1989). Archivo Manuel Gómez Pina. 


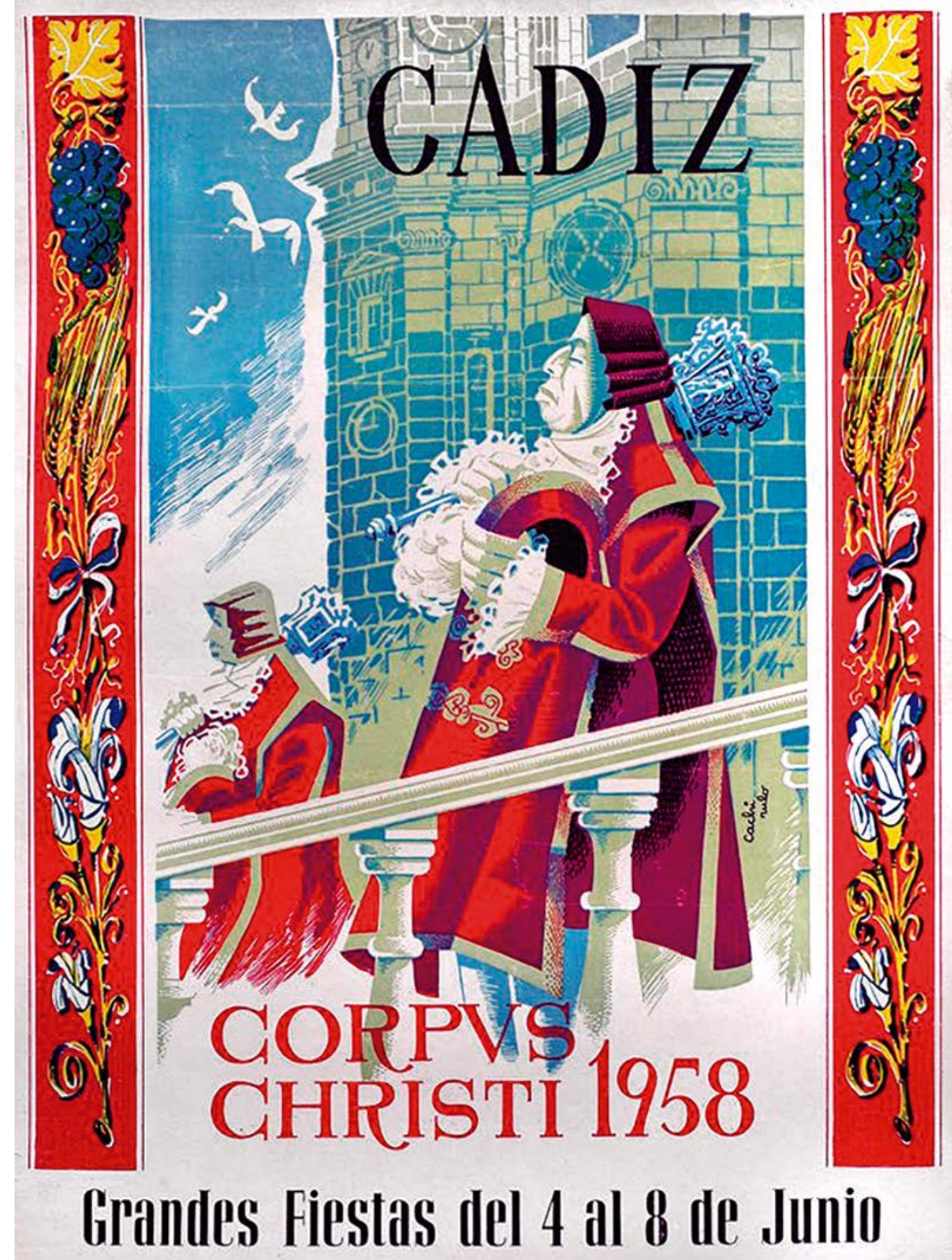

Fig. 42. Sebastián Moya 'Cachirulo’, cartel Cádiz, Corpus Christi (1958). Imprenta Repeto, Cádiz. Colección particular. 


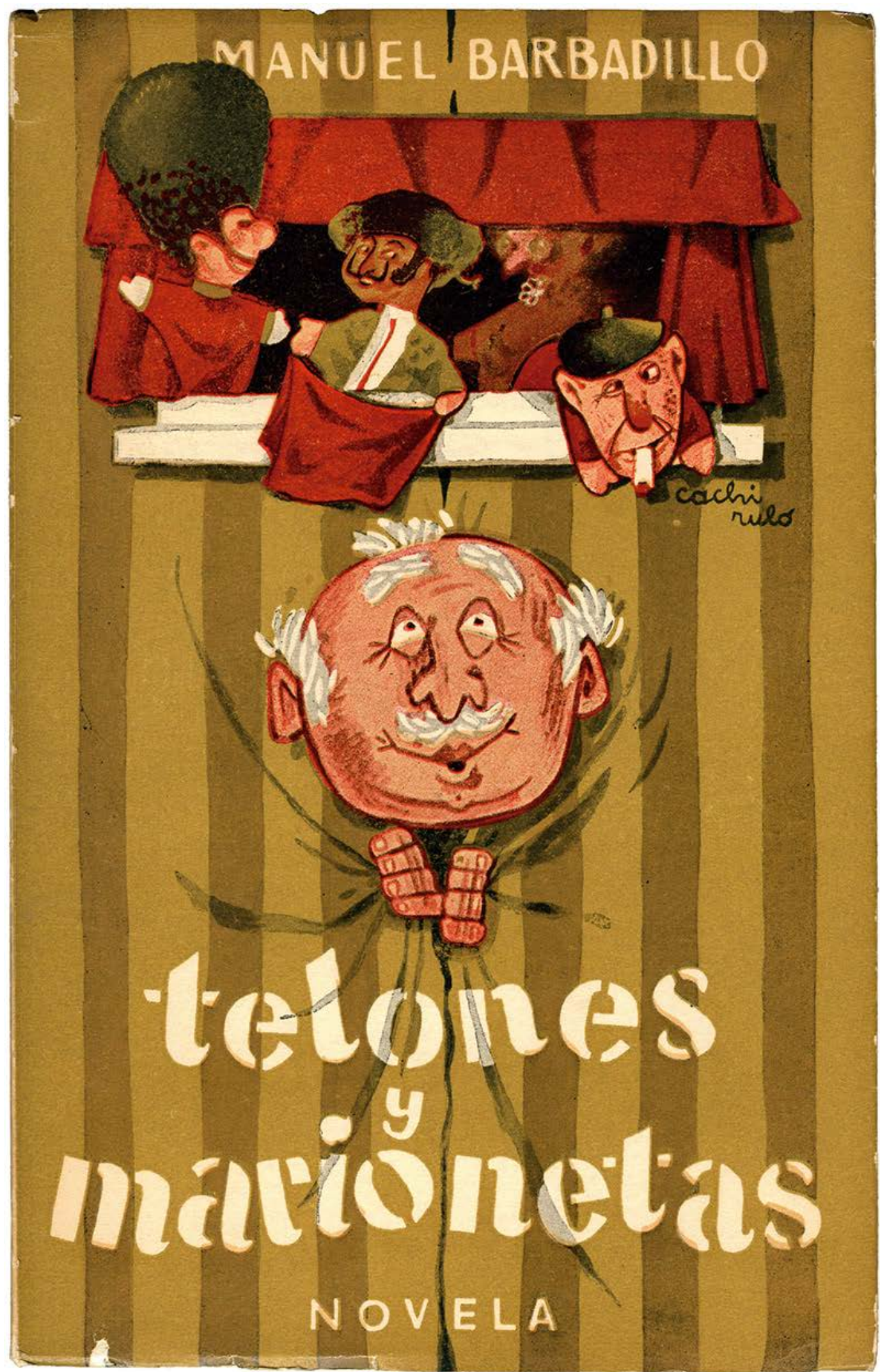

Fig. 43. Sebastián Moya ‘Cachirulo', cubierta del libro «Telones y marionetas», de Manuel Barbadillo, 1959. Editorial Jerez Industrial. Colección particular. 

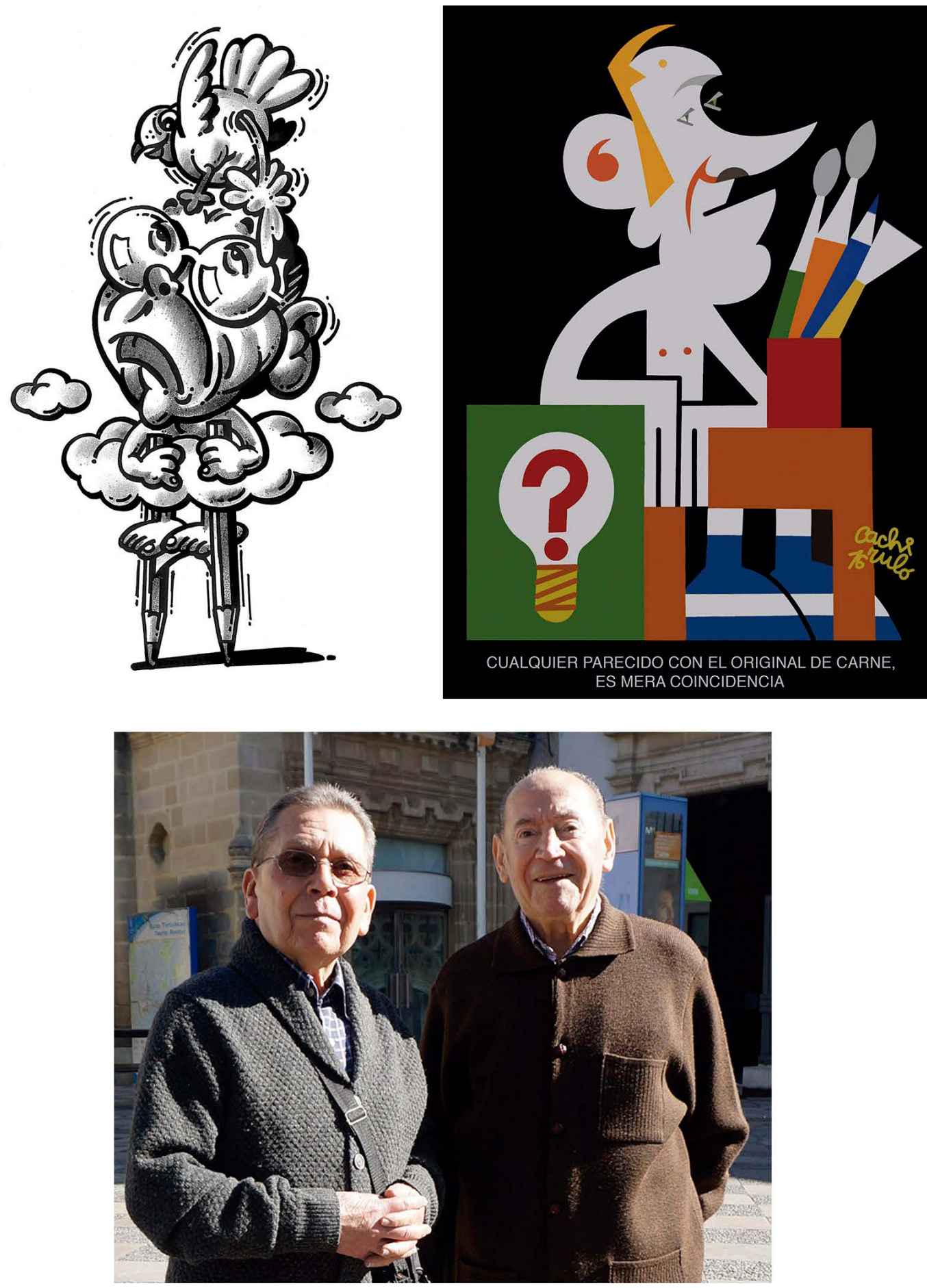

Fig. 44. Sebastián Moya 'Cachirulo', autocaricatura. Del libro «Estudio psicoestético de personajes Jerezanos (1를 parte)» Caja de Ahorros de Jerez (1984). Archivo Sebastián Moya.

Fig. 45. Sebastián Moya ‘Cachirulo', caricatura de José Benítez Troya. Archivo José Benítez

Fig. 46. Sebastián Moya y José Benítez Troya en 2017. Foto del autor. 


\section{Conclusiones}

La industria gráfica jerezana reunió durante décadas unas características específicas frente a otros lugares de nue stro país, y destacó en Andalucía de forma singular. El vino y sus derivados como productos de consumo no adquiere personalidad comercial moderna — dotada de un sistema de marcas y signos diferenciadores que lo singularicen frente a la competencia - hasta bien entrada la segunda mitad del siglo XIX. Para que esa «imagen propia» adquiriese valor, surgió todo un colectivo humano, profesional y empresarial que diera respuesta a dicha necesidad. Pero al mismo tiempo necesitó de un clima adecuado, social, cultural y artístico que sirviera de caldo de cultivo. Esta sociedad jerezana de finales del XIX y principios del XX fue el germen para que surgieran un extenso grupo de dibujantes que realizaron obras singulares de comunicación publicitaria e imagen de marca. Sus obras constituyen lo que hoy llamamos «ephemera»-etiquetas, reclamos, carteles, tarjetas, folletos, listados de precios- y todo aquel material que tiene una corta vida, casi todos impresos, y que están pensados para ser olvidados y destruidos una vez cumplido su cometido (Ramos Santana, 2018). Precisamente son estos soportes los que quizás sorprendentemente más nos relacionan con una época pasada, con nuestras experiencias vitales, con nuestros recuerdos. A las grandes obras se les dota de valor por ser trascendentes e intemporales, nos pueden hacer sentir emoción y placer estético, pero pertenecen a un mundo siempre distante. Estas piezas son fruto de sociedad industrial, de los productos fabriles que necesitan dotarse de nombre y de una imagen, y que conviven con nosotros. Por esto nos resultan cercanos.

Curiosamente, estos productos necesitaron ser diseñados, configurados, tanto a nivel formal como visual, y este proceso generó una actividad que es, en un amplio sentido, la que realiza el diseñador, en cualquiera de sus facetas. En los albores de la industrialización, los productos manufacturados se parecían demasiado a los objetos artesanales, recargados y visualmente complejos. La funcionalidad llegó más tarde al diseño industrial, con el «menos es más». Esta nueva necesidad de imágenes en el plano gráfico demandó recursos visuales que fuesen conocidos. Por eso, la iconografía pictórica de la época invade las representaciones visuales de los primeros productos impresos para publicidad. En el caso que nos ocupa, es frecuente encontrar escenas costumbristas, perfectamente asimiladas y aceptadas por los consumidores, y más en el caso de la iconografía del vino, el realismo pictórico muy del gusto victoriano se presenta como las escenas más representativas en etiquetas y carteles, al que hay que añadir el exotismo asociado a lo andaluz (majas, toreros, caballos, etc). Quizás es el cartel, en tanto que soporte más pictórico donde encontramos la influencia del Modernismo y las primeras síntesis visuales propias de la publicidad, que supieron explotar las posibilidades del medio litográfico. Las influencias artísticas del momento aparecen en los soportes publicitarios, en autores como Teodoro Miciano o Francisco Hohenleiter, y los recursos propios de medio gráfico (síntesis, fragmentación, simplificación, metáforas) en los trabajos de Capiello o más tarde en Manolo Prieto, entre otros. Sin embargo, la experiencia jerezana tiene factores que la singularizan. Por un lado, la vinculación a un producto concreto, que tiene una clientela polarizada entre el mercado internacional por un lado —británico especialmente-, y por otro local; con preferencias estéticas muy fijas y establecidas, y con un empresariado que, como norma, no es propenso a los cambios ni a las novedades. Pese a todo, la ciudad de Jerez vivió una fecundas épocas de florecimiento cultural, con una población diversa y cualificada, con un sistema formativo de talleres donde aprendices adquirían su oficio, acompañado de una escuela de Artes y Oficios que completaba dicha formación. La fractura de la Guerra civil acentuó un replegamiento sobre su propia identidad, con la desconexión y ruptura de influencias externas. Pese a ello, se produjo un relevo generacional que dio sus frutos, y el caso de los diseñadores y los dibujantes de Mamelón fueron un buen ejemplo de ello. Sobre todo, y porque ellos lo manifestaron así, vivieron disfrutando de lo que hacían... 


\section{Bibliografía Fuentes documentales}

ABC de Sevilla (1970). Bodas de Plata de la empresa Jerez Industrial, S.A. ABC de Sevilla, 12 de junio de 1970.

Arendt, Hannah (2018). Entre el pasado y el futuro. Ocho ejercicios sobre la reflexión política. Barcelona: Península/Austral.

El Bachiller Bambalina (1913). Las Artes Gráficas en Jerez. Madrid: Revista Nuevo Mundo de 24 de julio de 1913. Recuperado de: http://hemerotecadigital.bne.es/details. vm?q=parent\%3A0001252858\&lang=es\&s=953 [Consulta: julio 2019].

Gómez Díaz-Franzón, Ana (2018). Imagen publicitaria del Marco de Jerez (1868-1936). Un retrato de la época. Volumen I. Madrid: Universo de Letras.

González Gordon, Manuel Mำ (1970). Jerez-Xerez Sherish. Noticias sobre el origen de esta ciudad, su historia y su vino. Jerez: Gráficas del Exportador.

Halley, Ned (2005). The Wordsworth Dictionary of Drink: An A-Z of Alcoholic Beverages. Hertfordshire, Reino Unido: Wordsworth Editions Limited.

Jiménez, José Luis (2006). Mamelón: Ios diseñadores de la imagen del jerez. Jerez: La voz Digital. Recuperado de: https://www.lavozdigital.es/jerez/prensa/20060820/opinion_jer/mamelon-disenadoresimagen-jerez_20060820.html [consulta julio 2019].

López Marín, Enrique. «Manolo Prieto y el camino al diseño». En: AGUILAR JIMÉNEZ, Juan (2017) Lo que cuenta Novelas y cuentos. Las portadas de Manolo Prieto (1940-1957). Madrid: Experimenta.

López Marín, Enrique: «Estrategias de investigación en Diseño. Los constructos personales de George A. Kelly aplicados en el conocimiento de la metodología en procesos de diseño». En: Quaresma, José, Fernando Paulo Rosa Dias, Fernando (coord.) (2013) Investigação em Arte. Uma floresta muitos caminhos. Lisboa: CIEBA, Universidade de Lisboa.

Maldonado Rosso, Javier (1999). La formación del capitalismo en el Marco del Jerez: de la vitivinicultura tradicional a la agroindustria vinatera moderna (siglos XVIII-XIX). Madrid: Huerga \& Fierro Editores.

Melendreras, Emeterio R. (1949). Eso del "jerinac"... Revista Arte comercial, Madrid (27).

Pérez, Daniel; Jiménez, José Luis (2007). Los artistas que pintaron el vino. Jerez: La Voz Digital, 27/1/2007. Recuperado de:

http://www.lavozdigital.es/cadiz/prensa/20070127/cultura/artistas-pintaron-vino_20070127.html [consulta octubre 2015].

Pérez Mulet, Fernando (2004). «Comunicación e imagen: apuntes de arte gráfico en Jerez» Revista de Historia de Jerez, no 10. Jerez: Centro de Estudios Históricos Jerezanos.

Ramos Santana, Alberto (2018). Iconografía de etiquetas antiguas del vino del Marco del Jerez, Xérès, Sherry. RIVAR, 5 (14), 201-222.

Saldaña Trigo, José; Repeto Prieto, Juan L. (2009). La imagen del vino de Jerez. Historia gráfica de las bodegas de Jerez de la Frontera. Siglos XIX y XX. Sevilla: Junta de Andalucía, Consejería de Agricultura y Pesca.

Satué, Enric (1997). El diseño gráfico en España. Historia de una forma comunicativa nueva. Madrid: Alianza Forma.

Simó, Juan P. (2015). Manolo Valle, 'el marciano del dibujo'. Diario de Jerez, 25 de octubre de 2015. Recuperado de: www.diariodejerez.es/jerez/Manolo-Valle-marciano-dibujo_0_965604074.html 
Téllez Fernández, José, Ruiz del Castillo, Miguel (1900). Memoria presentada a la Sociedad de Artes Gráficas de Jerez de la Frontera por los obreros José Téllez Fernández y Miguel Ruiz del Castillo, con motivo de su viaje a la Exposición Universal de Paris para estudiar los adelantos en dichas artes. Jerez: Imprenta de Crespo Hermanos.

Virilio, Paul (1997). El cibermundo, la política de lo peor. Madrid: Cátedra, colección Teorema.

\section{Entrevistas}

Entrevista a Rafael Virués de Segovia y Llamas, 25 de octubre de 2013.

Entrevista a Sebastián Moya González y José Benítez Troya, 17 de noviembre de 2017.

Entrevista a Sebastián Moya González y José Benítez Troya, 30 de noviembre de 2017.

Entrevista a Juan Herrador Granero, 18 de enero de 2018.

Entrevista a Pedro Carabante Medina, 1 de febrero de 2018.

Entrevista a Manuel Cervera Pérez, 14 de febrero de 2018.

Entrevista a Carmen Valle Pérez, 29 de agosto de 2018.

Entrevista a Manuel Gómez Pina, 6 de septiembre de 2018.

Entrevista a Milagros Montes Machuca, 6 de septiembre de 2018. 